\title{
Identification of Materials and Pigments Used in Mural Painting of Rahim Abad Historic Garden \& Mansion in Birjand
}

\author{
Javad Abbasi*1, Roya Bahadori ${ }^{2}$, Mohammad Ali Bozorgmehr ${ }^{3}$, Seyyed Iraj Beheshti ${ }^{4}$, \\ Faranak Bahrololoumi ${ }^{5}$ \\ ${ }^{1} P h D$ candidate in conservation of cultural-historical objects, Tehran University of Art, Tehran, IRAN \\ ${ }^{2}$ Faculty member of Research Center for Conservation of Cultural Relics, Research Institute for Cultural \\ Heritage \& Tourism, Tehran, IRAN \\ ${ }^{3}$ Expert of Southern Khorasan General Administration of Cultural Heritage, Handicrafts and Tourism, \\ Birjand, IRAN \\ ${ }^{4,5}$ Expert of Research Center for Conservation of Cultural Relics, Research Institute for Cultural Heritage \& \\ Tourism, Tehran, IRAN
}

\begin{abstract}
This paper presents the results of the identification of the binder and pigments used in the mural paintings in Rahim Abad Historic Garden and Mansion in Birjand. Birjand was one of the most important governmental strategic cities in Qajar era (1789-1925 A.D.), and an important branch area of ancient Silk Road, which connected India to Europe. Many monuments, especially historical gardens have been remained in Birjand. Rahim Abad Historic Garden and Mansion is one of this gardens, which in the period of Amir Ismail Khan Shaukat Molk, was the location of Qaenat ruler to consider politics, businesses and accommodating foreign guests. The most important part in the Architectural decoration of Rahim Abad Historic Garden and Mansion is mirror-encrusted decorations, stucco and wall paintings. Due to diversity in building decorations and multiplicity of constructing periods in Rahim Abad Historic Garden and Mansion, identification of pigments and materials used in wall paintings is of a great evidential assistance in extracting chronological information. Wall painting is one of the Iran arts that based on the signs of old paint can be pursued to pre-history. One of the most important issues in the study of historical paintings, especially wall painting, is the identification of the nature of paintings used to decorate the walls. Pigments identification is also important not only from the perspective of archeology, but also in terms of the history of art and knowledge of degradation processes and the development of monument conservation strategies is also important. Scanning electron microscopy in combination with energy dispersive X-ray microanalysis (SEM-EDX), Fourier transform infrared spectroscopy (FTIR), Polarized light microscopy (PLM), X-ray diffraction (XRD) and handheld X-Ray Florescence spectroscopy (micro-XRF) were used for the characterization of the compound and structure of the paint layers of samples taken from mural paintings. In fact, chemical and physical analysis, provides useful information from spectrum of pigments in a region and recognizing color preparation techniques and its application. Also before proceeding restoration, the accurate information from the chemical composition of materials used in object is required. According to the obtained results, mixture of gypsum and calcite as a substrate layer, red lead $\left(\mathrm{Pb}_{3} \mathrm{O}_{4}\right)$, mixture of malachite $\left(\mathrm{CuCO}_{3} \cdot \mathrm{Cu}(\mathrm{OH})_{2}\right)$ and Prussian blue $\left(\mathrm{Fe}_{4}\left(\mathrm{Fe}[\mathrm{CN}]_{6}\right)_{3}\right)$, ultramarine $\left(\mathrm{Na}_{8-10} \mathrm{Al}_{6} \mathrm{Si}_{6} \mathrm{O}_{24} \mathrm{~S}_{2-4}\right)$, and mixture of two metals, copper and zinc, as the pigments were used. Also, an adhesive like animal glue was that of common materials in Qajar period, as well as used to substrate color. Such pigments are further evidence
\end{abstract}

*Corresponding author: javad_abbasi1991@yahoo.com 


\section{JOURNAL OF RESEARCH ON ARCHAEOMETRY}

that the mural painting of this monument are from the late Qajar. Oil was used as binder or varnish in this painting and there is in all of the samples. One of the interesting points of the materials used in the paintings was the application of a mixture of pigments to create colors with different tonalities. Another point is the use of imported pigments such as Prussian blue, along with other traditional pigments that were common in of that era. Also, the microscopic examination of golden color indicates the presence of chalcopyrite in this pigment. These compounds exist due to the corrosion of copper metal in golden color, and usually appear in golden colors obtained from two metals alloy, such as copper and zinc, by creating green color in a golden background.

Keywords: Pigment, Mural Painting, Rahim Abad Historic Garden and Mansion, Birjand, SEM-EDX, FTIR, PLM, XRD, Micro-XRF. 


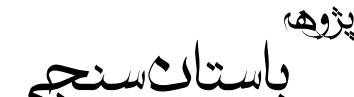

تاريخ دريافت: تاريخ يديرش: و

مقاله يُزوهشى نشماره

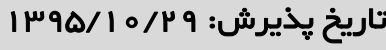

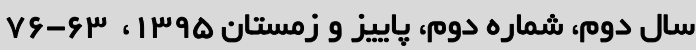

شناسايى مواد و رنكَدانههاى به كار رفته در نقاشىهاى ديوارى مجموعه باغ و عمارت تاريخى رحيمآباد بيرجند

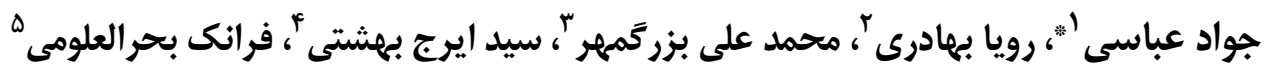

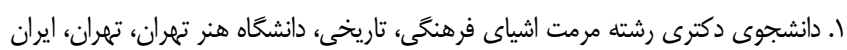

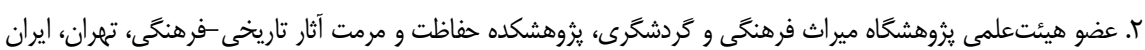

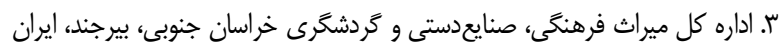

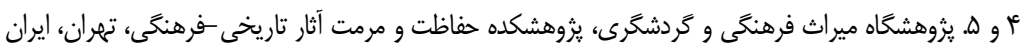

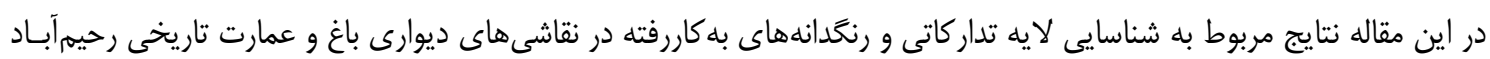

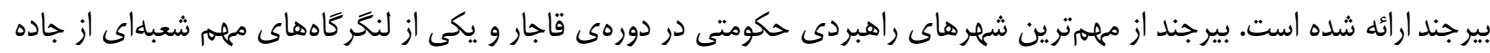

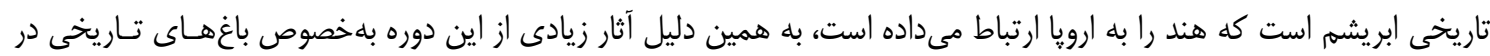

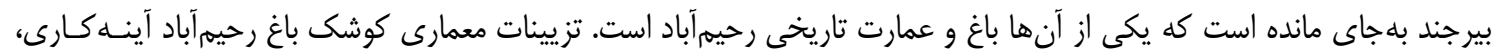

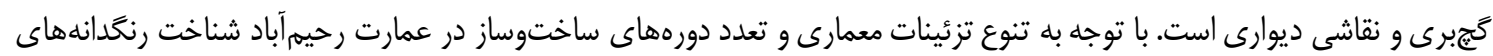

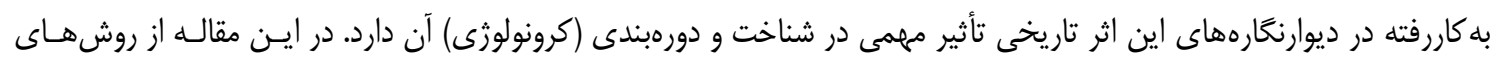

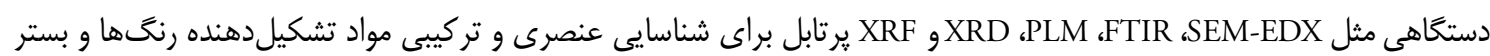

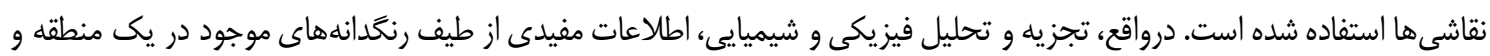

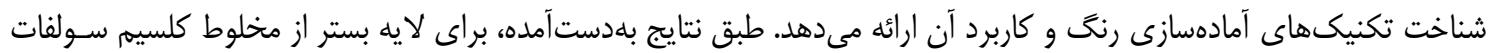

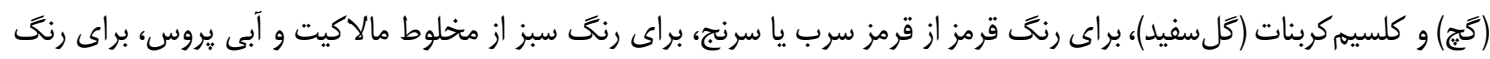

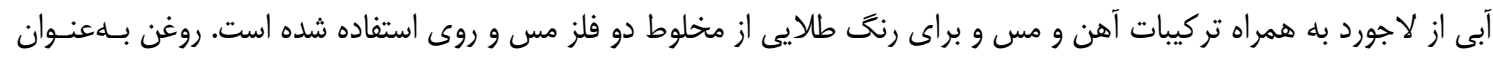

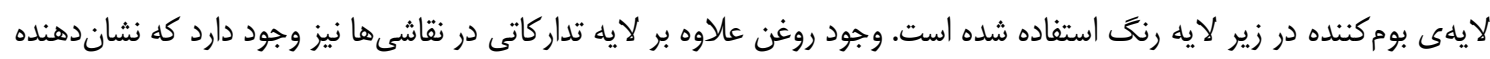

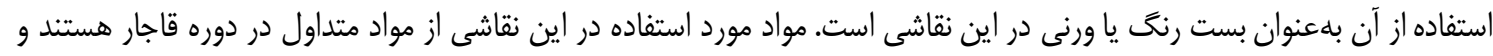

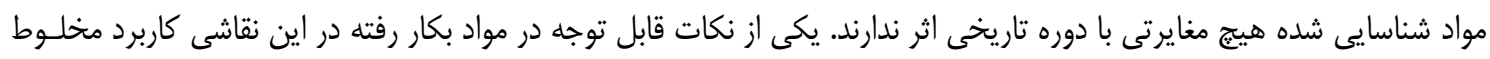

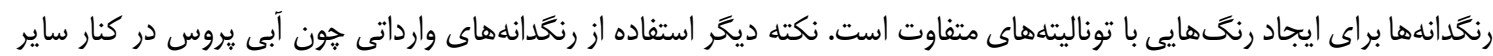

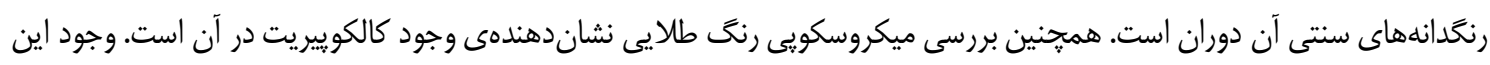

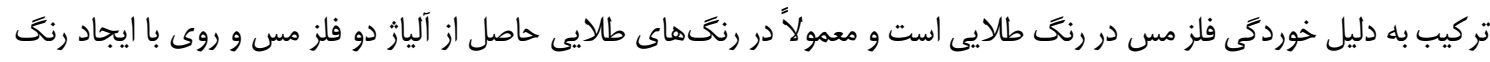
سبز در سطح رنخ طلايى نمايان مى شود.

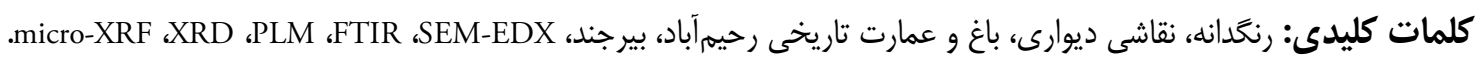

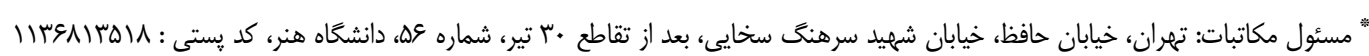
بست الكترونيكى: javad_abbasi1991@yahoo.com

(C) حق نشر متعلق به نويسنده(كان) است و نويسنده تحت مجوز Creative Commons Attribution License به مجله اجازه مىدهد مقاله خاب شده را با ديكران به اشتراك بخذارد منوط بر اينكه حقوق مؤلف اثر حفظ و به به انتشار اوليه مقاله در اين مجله اشاره شود. 
رنحَدانههاى به كاررفته در آن را روشن سازد. از طرفى بـاــا

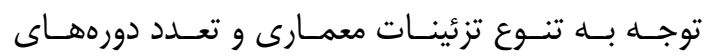

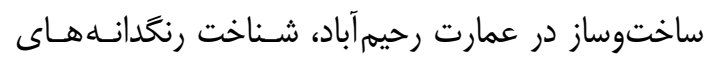

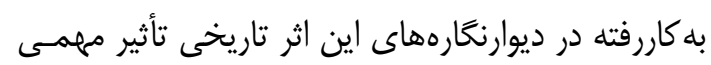
در كاهنغارى آن دارد.

\section{r. بيشينه تحقيق}

مهمترين روشهايى كه براى شناسايى رنكدانههـا بكـار

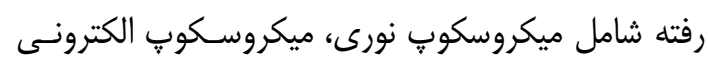

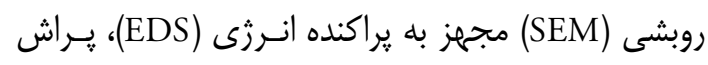

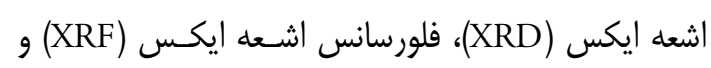

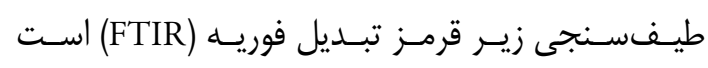
Darwish, 2013; Franquelo Mazzocchin et al., 2003) (et al., 2009;

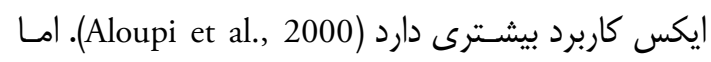

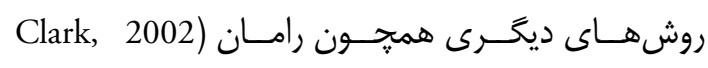
Bruder et al., 2007; Vandenabeele et al., 2005; Bicchieri et al., ) و ميكرو رامان (Irazola et al., 2012;

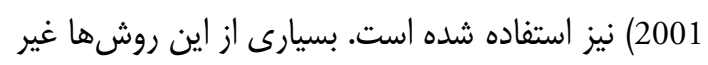

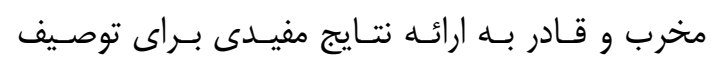
رنخدانهها هستند.

درباره مواد بهكار رفته در نقاشىهاى ديـوارى دورهى

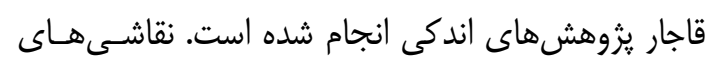

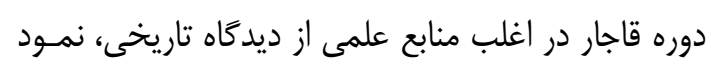

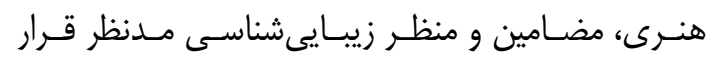
كرفتهاند (Azhand, 2006; Diba, 1989; Floor, 1999).

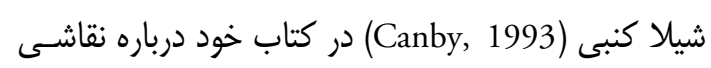

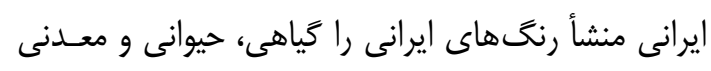

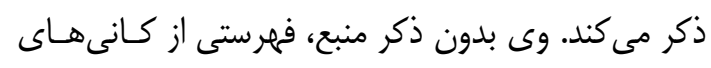

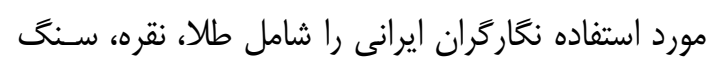

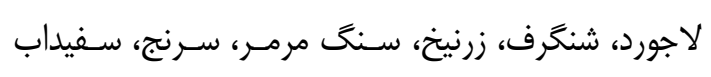

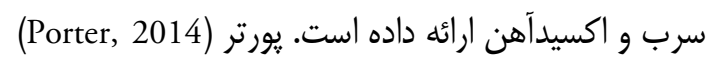
نيز در بررسى ديوارنغارهها و سفالينهها و شباهت آنها باريا

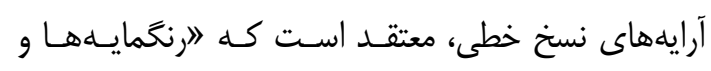

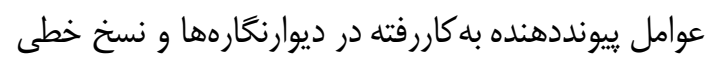
يكسان استه يورتر بر همين اساس و با استناد به متـون

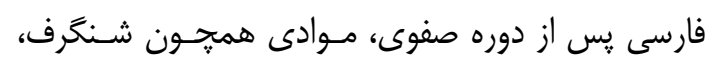

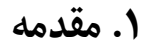

نقاشى ديوارى ازجمله هنرهاى ايران است كه بر اسـاس

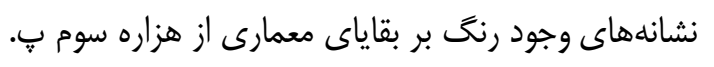

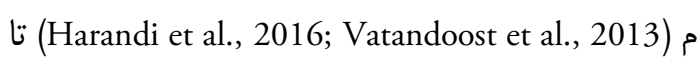

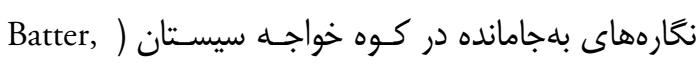

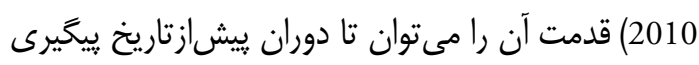

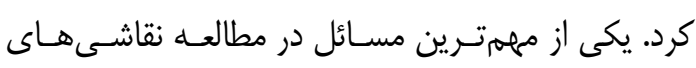

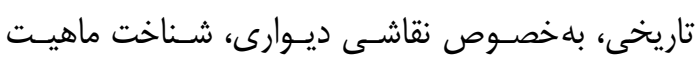

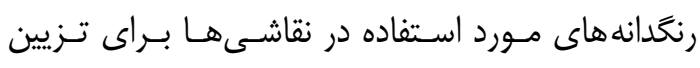

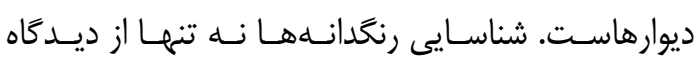

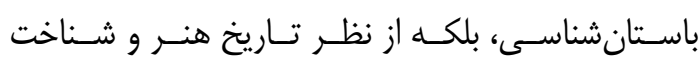

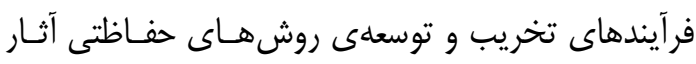

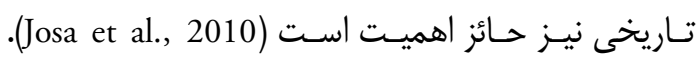
بلهور كلى دو دليل اصلى براى مرمتخــــان و حفـاظتكران

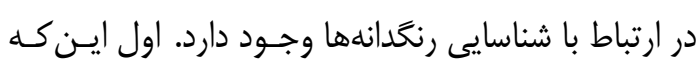

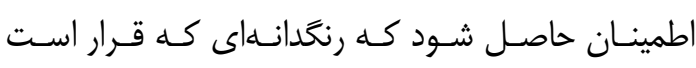

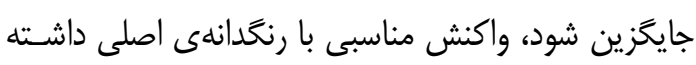

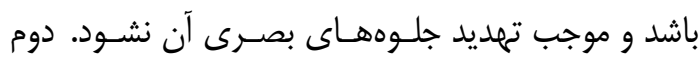

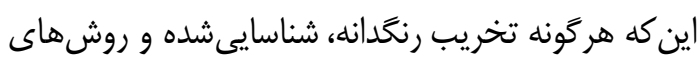
درمان مناسب با آن در نظر ترفته شـود (Clark, 2002). درواقع، تجزيه و تحليل فيزيكى و شـيميايى، اطلاعـات

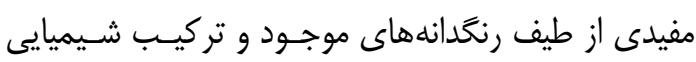

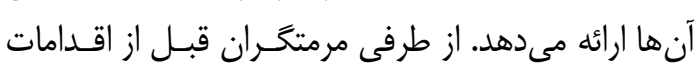

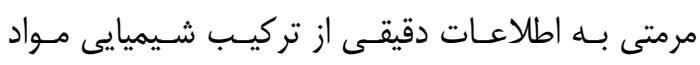

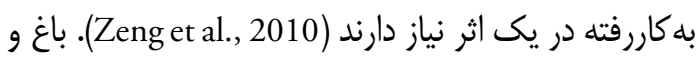

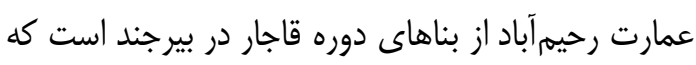

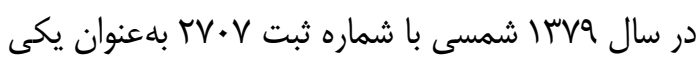

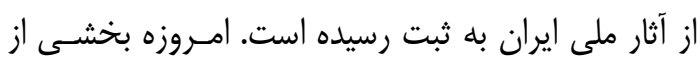

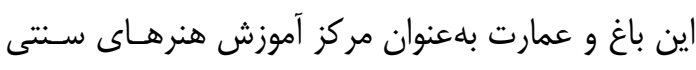

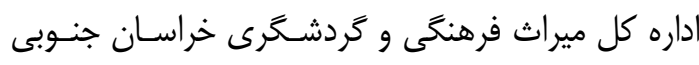

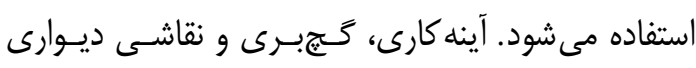

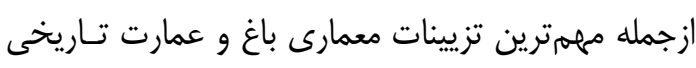

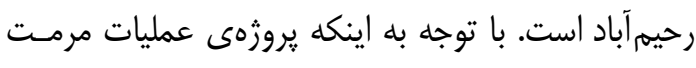
نقاشىهاى ديوارى اين بنا در جريان بود، هدف از مطالعه برانه

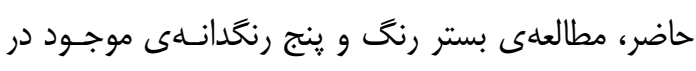

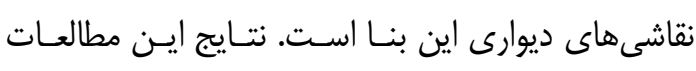

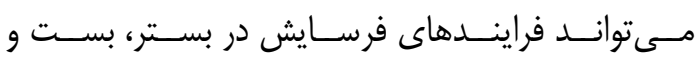

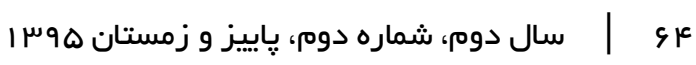


موفق به شناسايى آبى لاجورد، سفيد سرب و كَلســيد

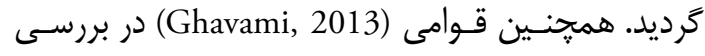
نقاشىهاى ديوارى خانه اخوان حقيقى كه از بناهاى دوره FTIR, XRF, XRD قاجار در اصفهان است با استفاده از أنان

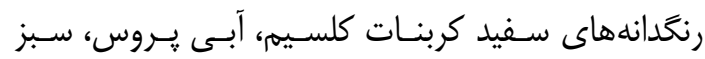
مالاكيت و قرمز سرنج را تشخيص داده است.

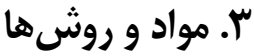

در اين يزوهش براى رسيدن به اهـــاف از روش تجربسى

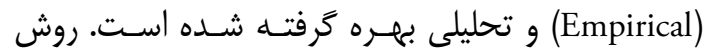
كردآَورى اطلاعات در اين يزوهش؛ مطالعات كتابخانهاى

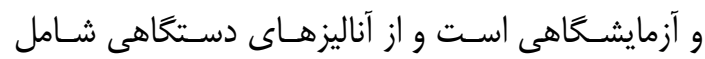

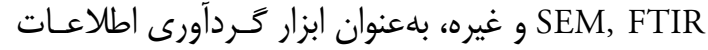
استفاده شده است. براى آناليز عنصرى رنخدانههاى قرمز، سبز و آبى از دستخاه SEM-EDS استفاده شـد. دستختاه مورد استفاده در اين آناليزها TESCAN ساخت جمهورى آناهي קك، مجهز به دستخاه آناليز عنصرى RONTEC بود.

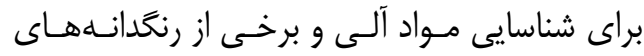
معدنى از دستخاه FTIR استفاده شد. دستخاه مورد استفاده

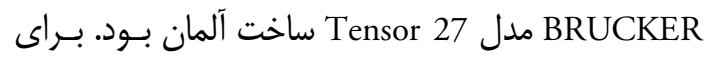

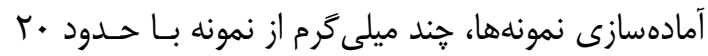

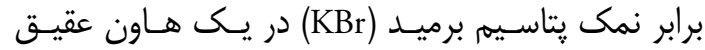

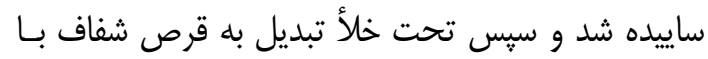

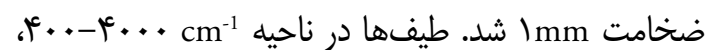

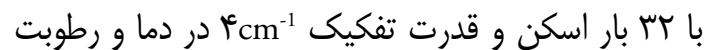
اتاق ثبت شدند. در مطالعه رنخدانههاى معدنى بـه دليـل

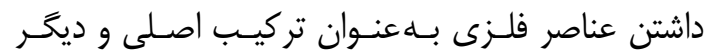
خصوصيات كانى هاى فلزى لازم است كه نمونه همزمان در جند نور مختلف مطالعه شود.

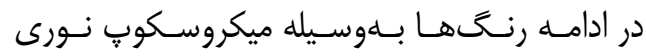

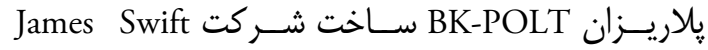

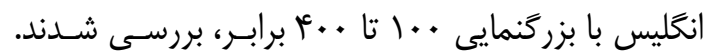

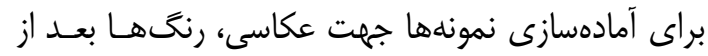

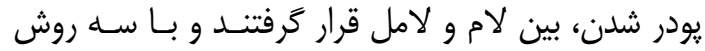

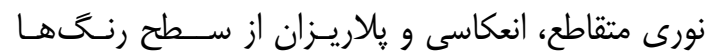

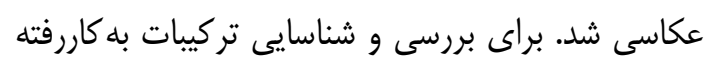

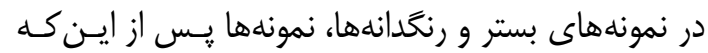

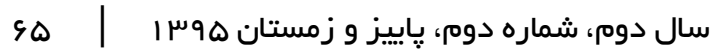

زنخار، طلا، لاجـورد و زرنسيخ را بـراى ديوارنخـارى نـام

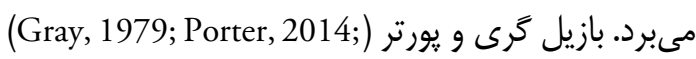
با استناد به رسالههاى دوره صفويه و قاجار اثبات مى كنند

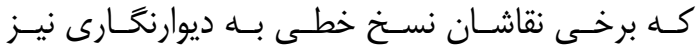

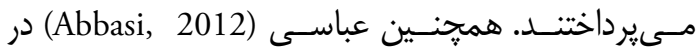

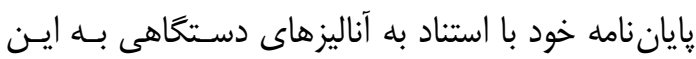
موضوع اشاره كرده است كـه در دوره قاجـار بسـيارى از

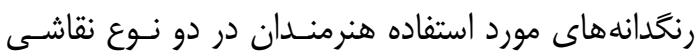

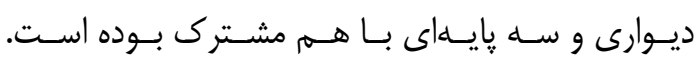
وطندوست و همكاران با استناد به رسالههاى دوره قاجار،

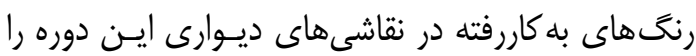

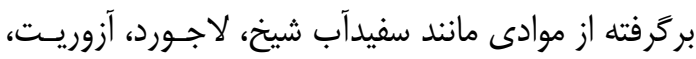
آبى خرده شيشه (اسمالت)، سبز مس يا زنغار، مالاكيـت،

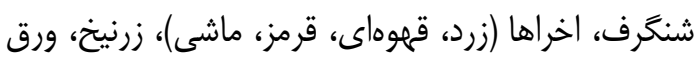

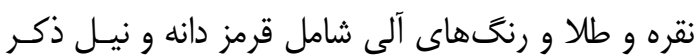
كردهاند (Vatandoost et al., 2013). بايد توجه داشت كه في به دليل افزايش تجارت با ارويا، رنخدانههاى مصنوعى كه به

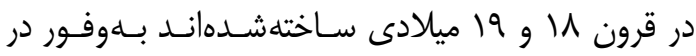
ديوارنغارههاى دوره قاجار مورد استفاده قرارگ فتنهاند. براى

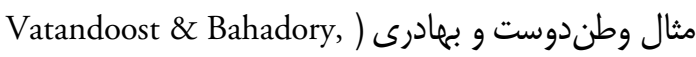

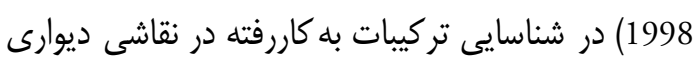

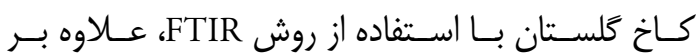

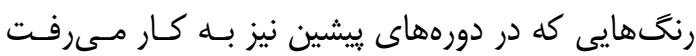

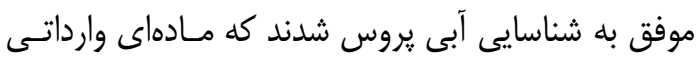

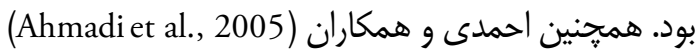
در بررسى نقاشىهاى ديوارى عمـارت باغتهـهـ جـوق در

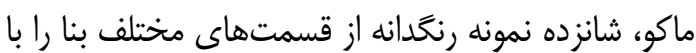
روش ييكسى (PIXE) بررسى كردهاند. در اين بنا از ورق

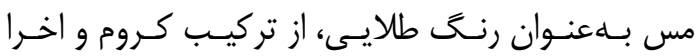

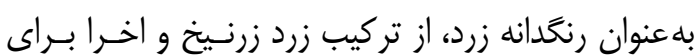
ساخت رنخ كروم، از تركيب سبز سيلو و مالاكيت بـراى زئن

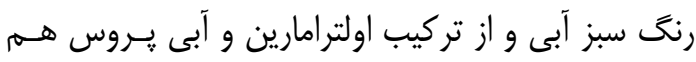

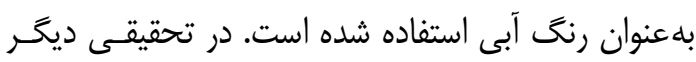

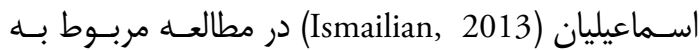
رنكدانههاى نقاشىهاى ديوارى تكـفام شانشـين خانـهـ

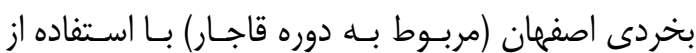

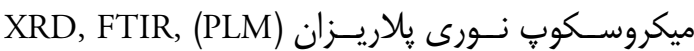


اوليه باغ احتمالاً به دوره زنديه يا اوايل قاجاريه برمى ترد دار.

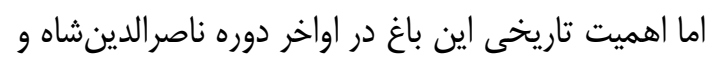

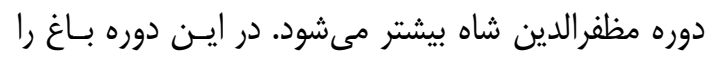

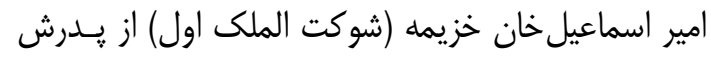

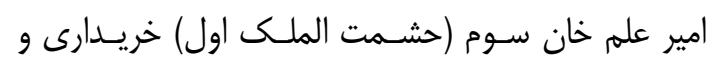
بخشهايى به آن اضافه كرده و از آن بهعنـوان اقامتحَـاه

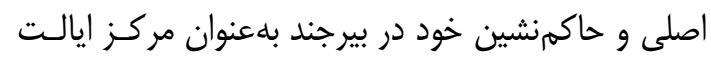

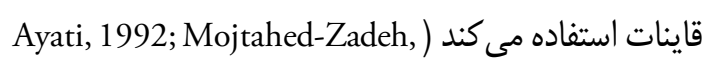
(2004; Yate, 1900 اتفاقاتى كه در آن افتاده، در تاريخ منطقه تأثير كذار بـودهد است (Ayati, 2012). در تزيينات معمارى بـاغ و و عمـارت

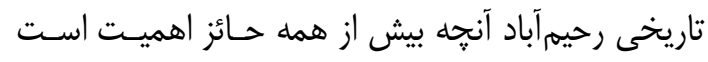

$$
\text { آينهكارى، تجبرى و نقاشى ديوارى استـان. }
$$

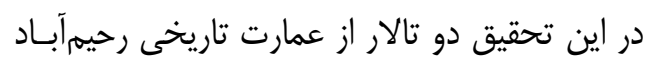

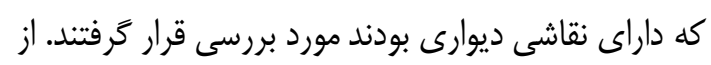
بستر نقاشـى و رنـحَهـاى طلايسى، قرمـز، آبـى و ســبز به كاررفته نمونهبردارى شد. با توجه به اينكه تمام رنغخها

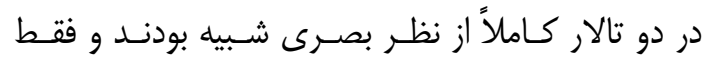

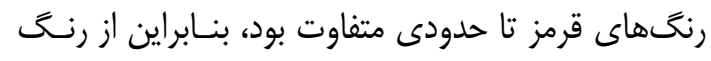

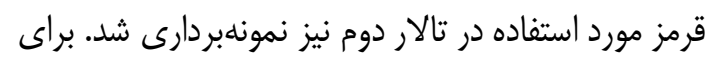

بهاصورت يودر ريز درآمدند با دستـاه يـراش يرتـوايكس

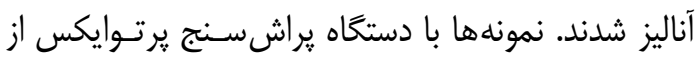
نوع يـودرى مـدل T2T متعلـق بــه شـركت SIEFERT

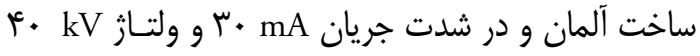

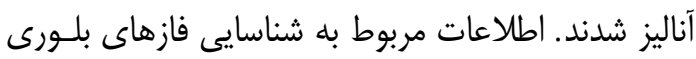

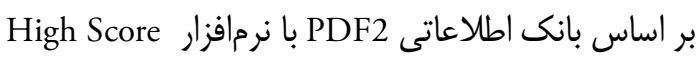

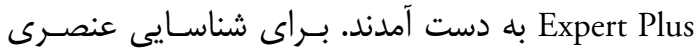

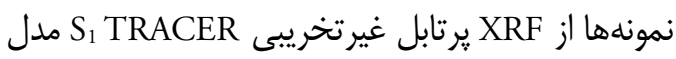

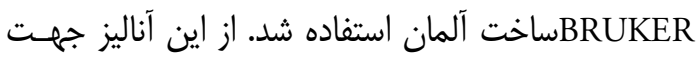
تجزيهى عنصرى رنخ طلايى استفاده شد. در اين روش الئ اليز

$$
\text { هيج گَنه نمونهبردارى صورت نمى كيرد. }
$$

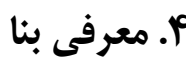

مجموعه باغ و عمارت تاريخى رحسيهمآبـاد دركذشـته بـا

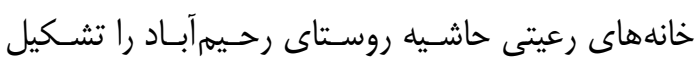

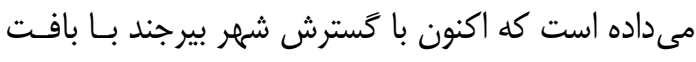

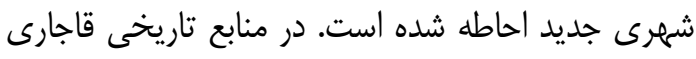

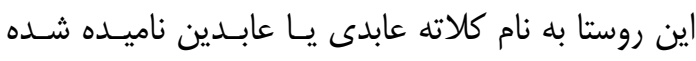
(Mojtahed-Zadeh, 2004; Yate, 1900) بdعنوان رحيهآباد شناخته مى شود (شكل (-1-1. (Mig). بنيان

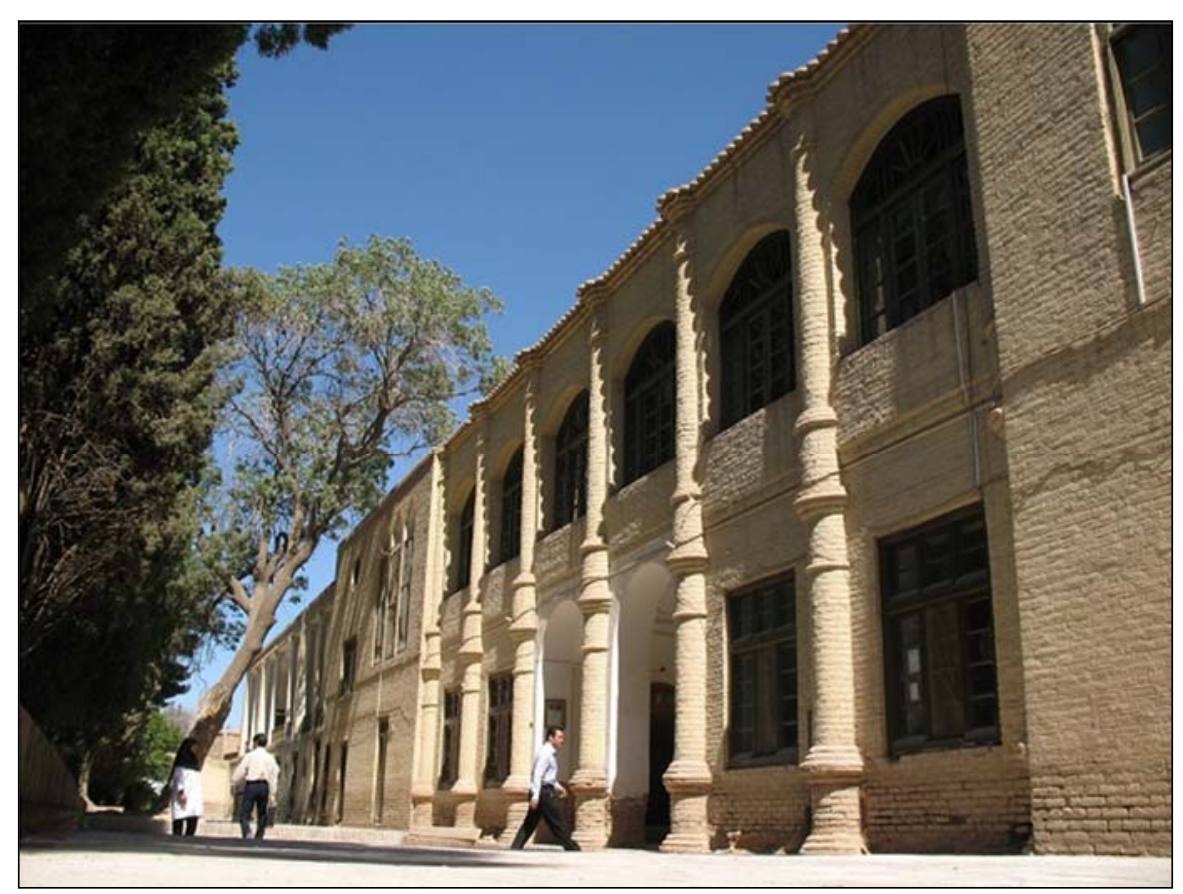

شكل ا: باغ و عمارت تاريخى رحيم|آباد بيرجند

Fig. 1: Rahim Abad Historic Garden \& Mansion in Birjand 


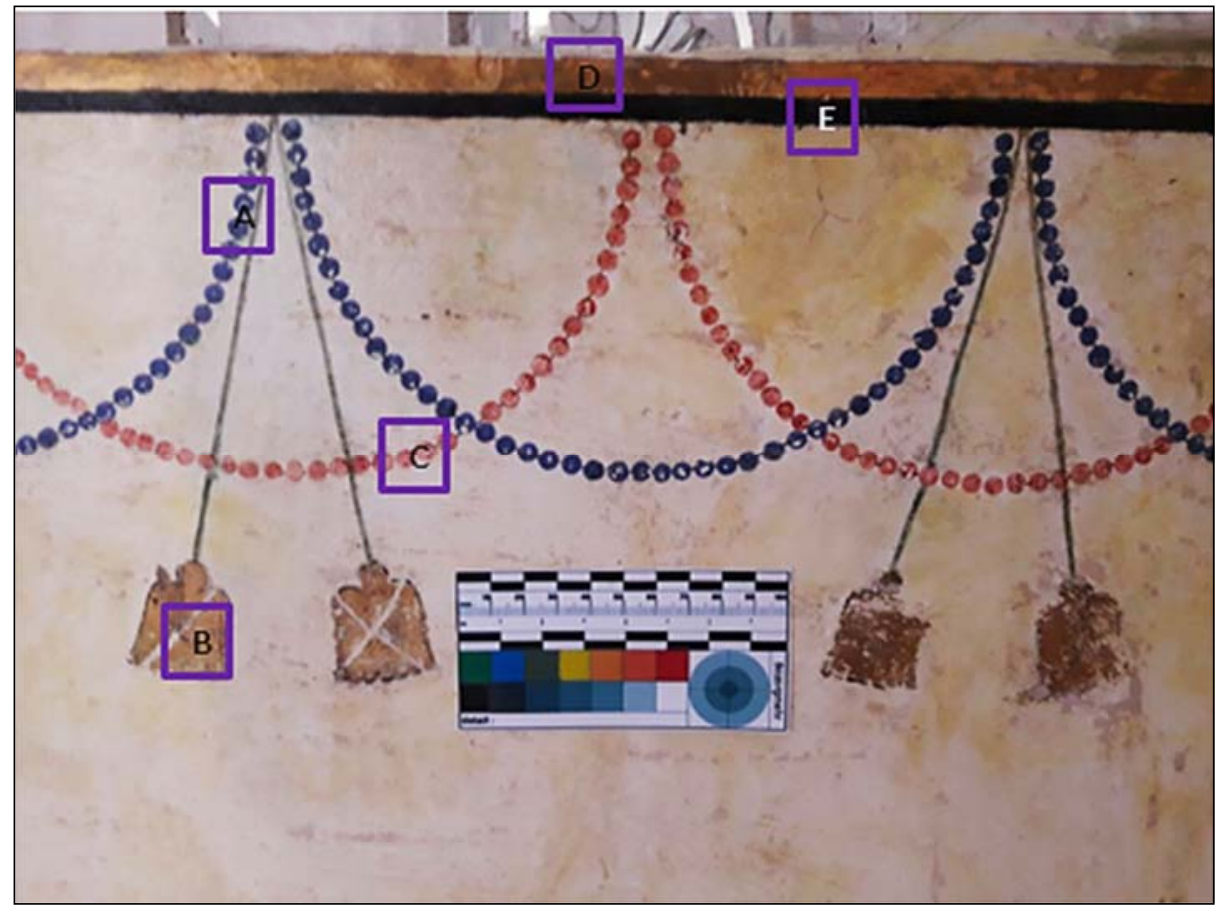

شكل ז: نمايى از رنحَهاى بلكاررفته در نقاشى ديوارى مجموعه باغ و عمارت تاريخى رحيمآباد بيرجند (عكس از جبهه شرقى تالار)؛ A: رنح

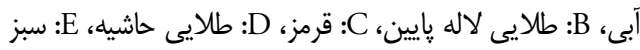

Fig. 2: A view of the colors used in Rahim Abad Historic Garden \& Mansion in Birjand wall paintings (Photo from the eastern side of Hall); A: blue, B: Golden Tulip Low, C: red, D: Golden margins, E: Green

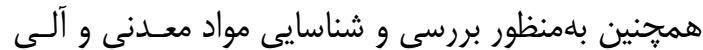

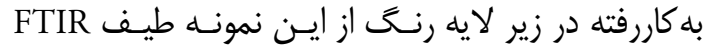

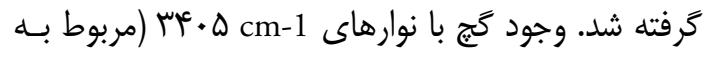

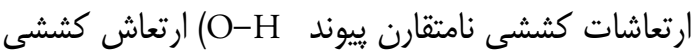

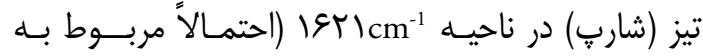

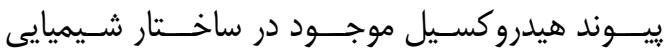
1110 cm cm (CaSO $4.2 \mathrm{H}_{2} \mathrm{O}$ و

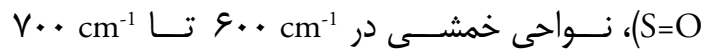

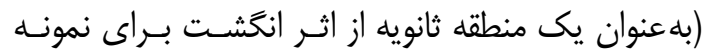

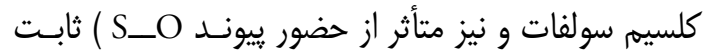

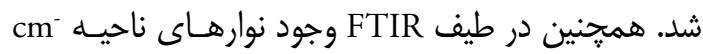

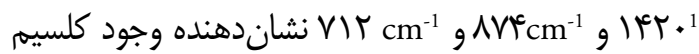

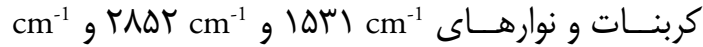

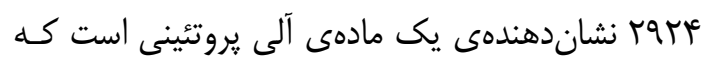

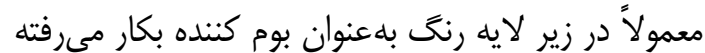

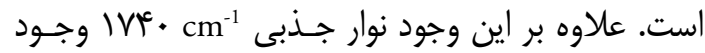
روغن را نيز نشان مىدهد. طيف FTIR لايه تداركاتى در
نمونهبردارى تا جايى كه امكان داشت لايه رنگ از بسـتر

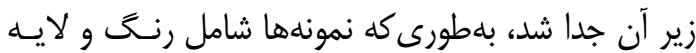

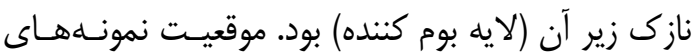
مورد بررسى در شكل r مشخص شده است.

\section{ه. نتايج و بحث در يافتهها}

در اين بخش از مقاله نتايج حاصل از شناسـايى مـواد و

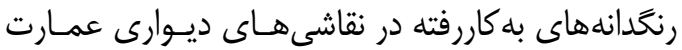
تاريخى رحيمآباد، در قالب تصاوير، جدول و نمودار ارائه و تحليل مى شود.

ه- ( شناسايى لايهى بستر و ماده بوم كنتده (لايهى زير رنَ) به روش XRD و FTIR

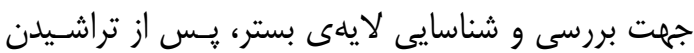
رنخ از سطح بستر، از آن طيف XRD گرفته شد. در نتايج

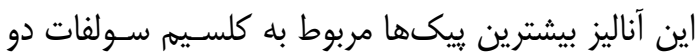
آبه $\left(\mathrm{CaSO}_{4} \cdot 2 \mathrm{H}_{2} \mathrm{O}\right)$

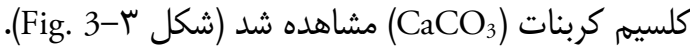

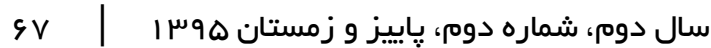




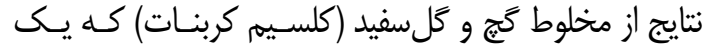

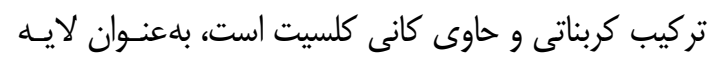

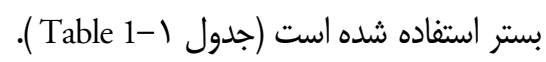

شكل ع أمده است. كل سفيد هم مى تواند بعنــوان يركنتــه

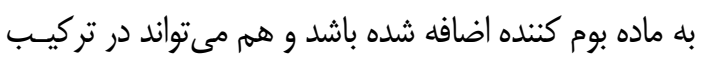

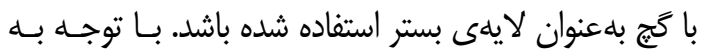
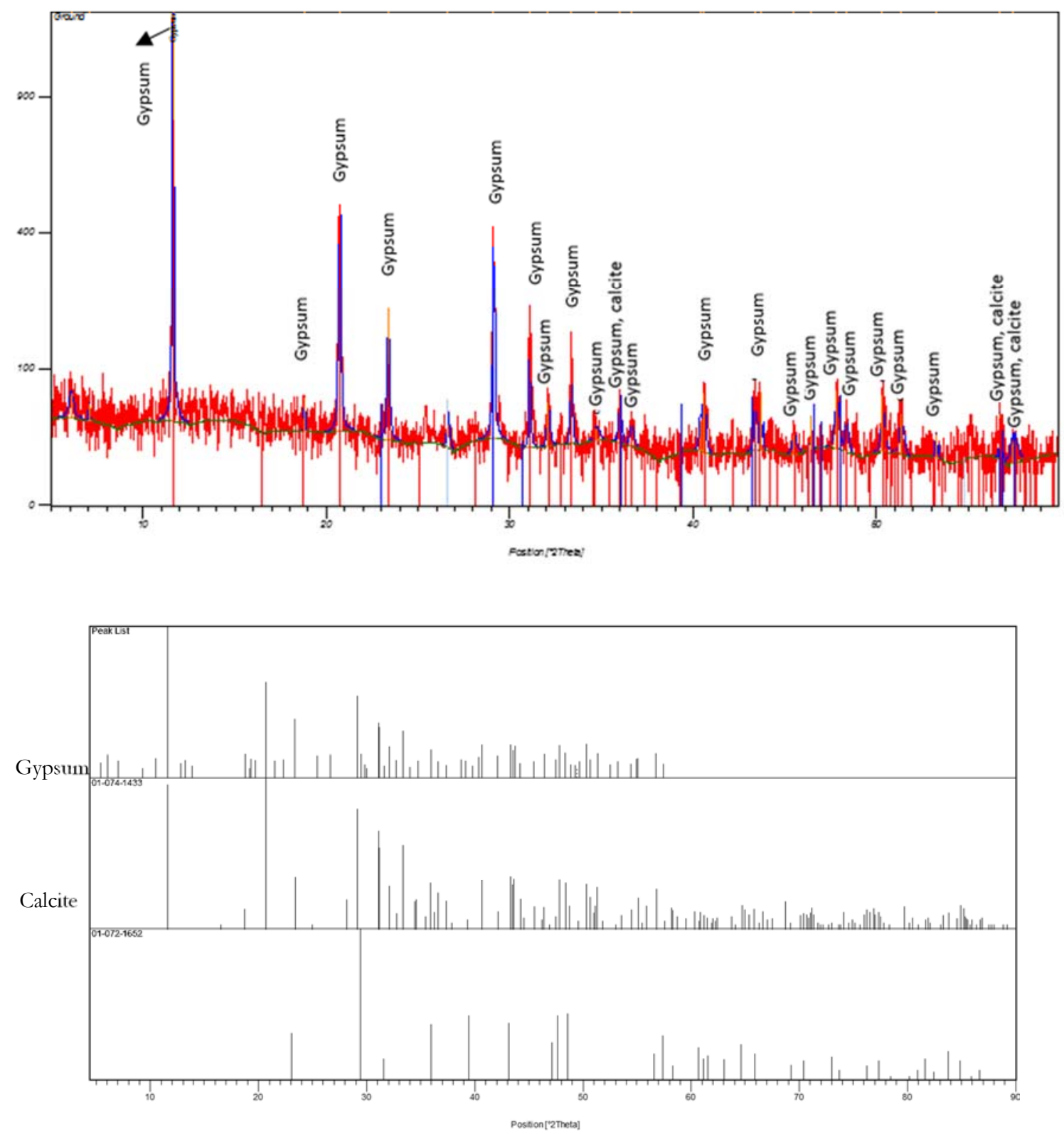

شكل سّ: طيف XRD لايه تداركاتى بهكار رفته در زير لايه رنح و مقايسه آن با طيفهاى مرجع

Fig. 3: XRD spectra of substrate layer and comparison with reference spectra

جلدل ا: تركيبات شناسايىشده در لايه تدار كاتى با XRD

Table 1: compounds identify of substrate layer with XRD

\begin{tabular}{|c|c|c|c|}
\hline Ref. Code & Score & $\begin{array}{c}\text { فرمول شيميايیى } \\
\text { Compound Name }\end{array}$ & $\begin{array}{c}\text { Chemical Formula } \\
\text { Cans }\end{array}$ \\
\hline $01-074-1433$ & 59 & Gypsum & $\mathrm{Ca}\left(\mathrm{SO}_{4}\right)\left(\mathrm{H}_{2} \mathrm{O}\right)_{2}$ \\
\hline $01-072-1652$ & 22 & Calcite & $\mathrm{CaCO}_{3}$ \\
\hline
\end{tabular}




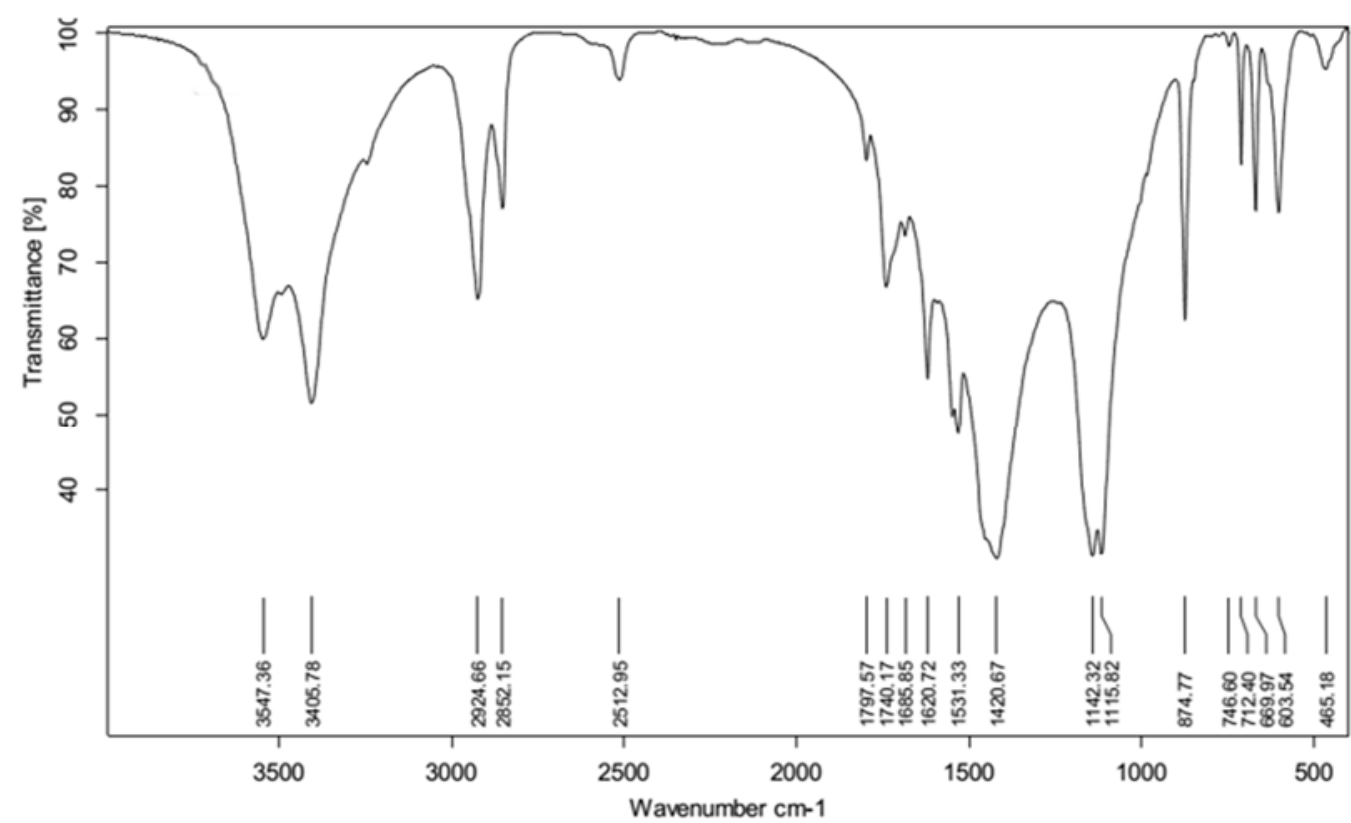

شكل fأ: طيف FTIR لايهى تدار كاتى

Fig. 4: FTIR spectrum of substrate layer

دوران باستان تا به امروز مورد اسـتفاده بـوده و از اولـين رنحدانههايى است كه بلصورت مصنوعى توليد شده است .(Eastaugh et al., 2012, p. 235; Mcbride, 2002) سرنج از رنحَدانهاى قديمى است و شايد بتوان كفت كه

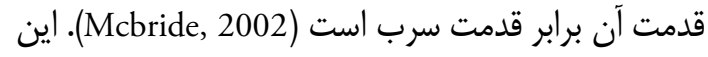

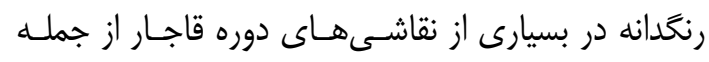

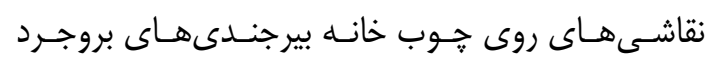

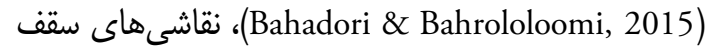
Bahadori ( جوبى خانه تاريخى شفيعى اردكانى در شيراز

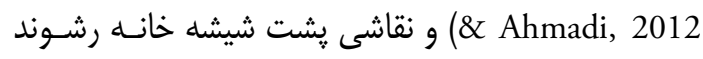
قزوين (Mozaffari et al., 2010) بكار رفته است.

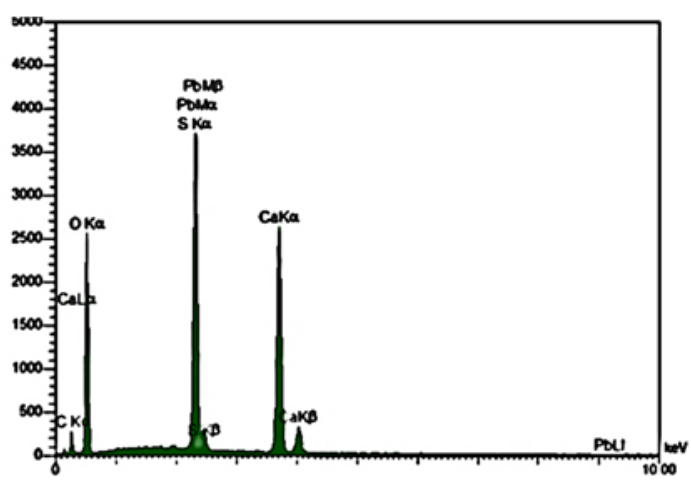

شكل ه: طيف EDX رنغ قرمز

Fig. 5: EDX spectrum of red color

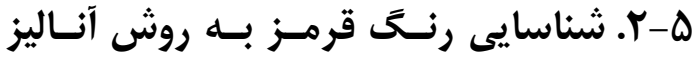

عنصرى EDX

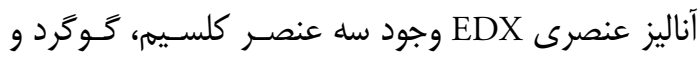

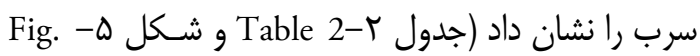
5). وجود كلسيه و گَوَّد به علت حضور گَج در لايه زير

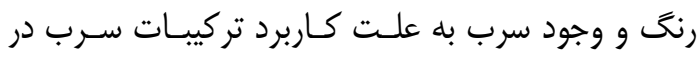
رنح قرمز است. بلهنظور شناسايى نوع تركيب بله كار رفته

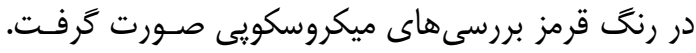

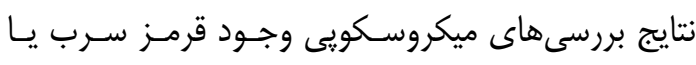

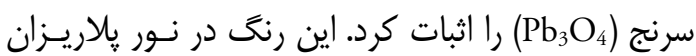

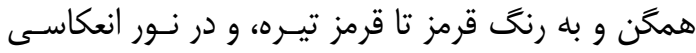

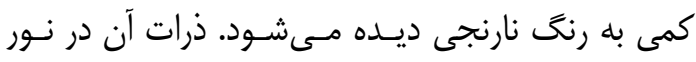

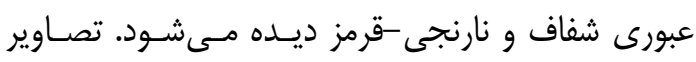

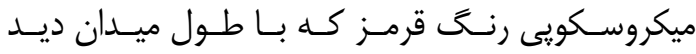

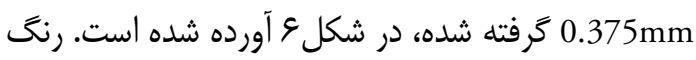
قرمز بكار رفته در هردو تالار سـرنج بـود و نتـايج آنـاليز

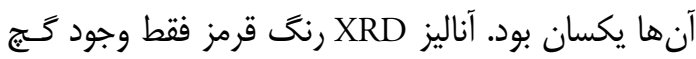

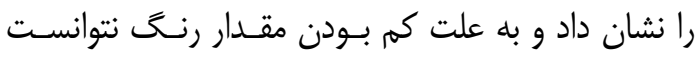
رنح را شناسايى كند. نام شيميايى سرنج تتراكسيد سرب است و كردى به

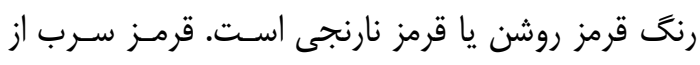

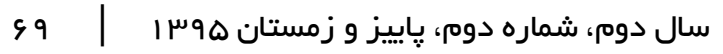




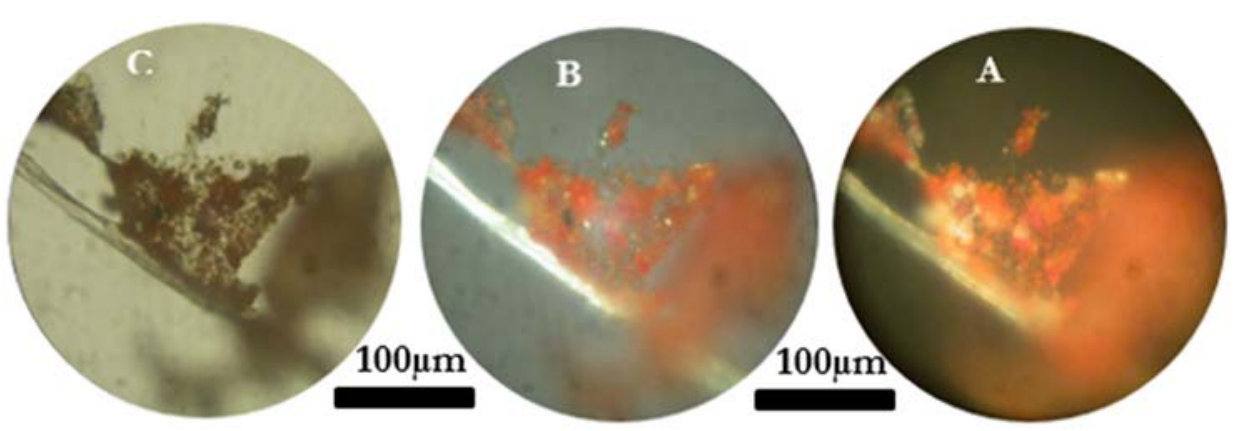

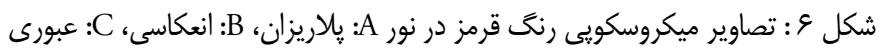

Fig. 6: Red Microscopic Images in the Light: A: Polarizing, B: Reflection C: Transmission

مالاكيـت از دوران باسـتان مــورد اسـتفاده بـوده و

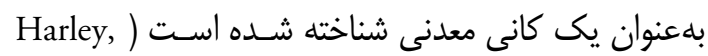

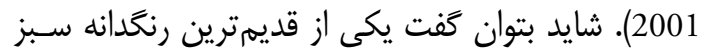

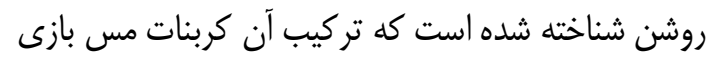
طبيعى (معدنى)، است. مالاكيت بلورى (منو كلينيك) است سلت

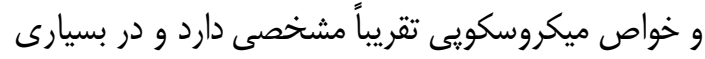

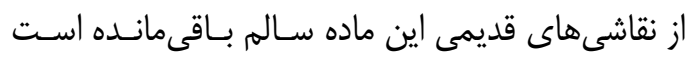

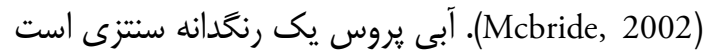

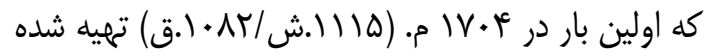
اسـت (Riederer et al., 1997). ايـن رنحدانـه در دوره

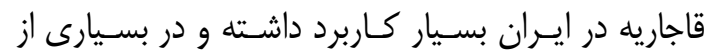

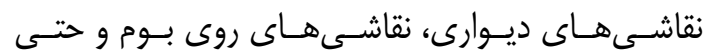
نقاشى هاى روى كاغذ به كاررفته است (Alizadeh, 2012).

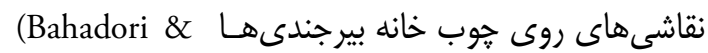
Bahrololoomi, 2015)

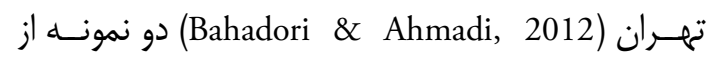
كاربردهاى اين رنتى در نقاشىهاى دوره قاجار است.

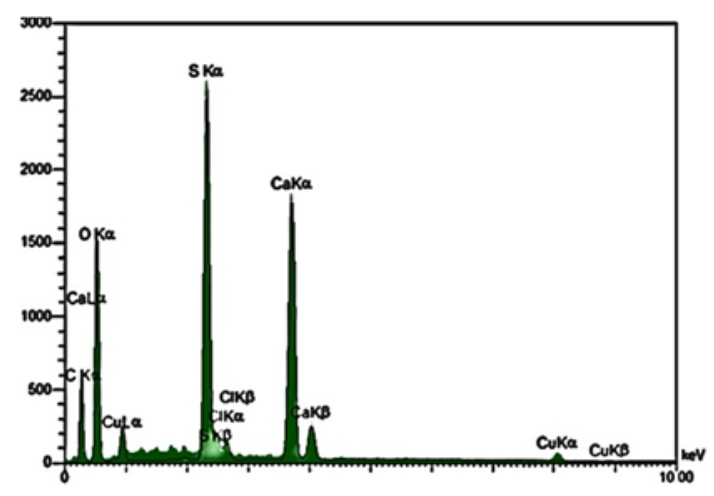

شكل V: طيف EDX رنح سبز

Fig. 7: EDX spectrum of green color

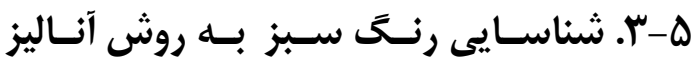 عنص EDN}

براى شناسايى رنغ سبز با توجه به مقدار بسيار كم نمونه،

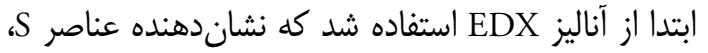

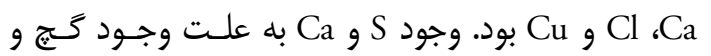
عنصر Cu بيانگر احتمال استفاده از تركيبات مسس اسـت ولهود

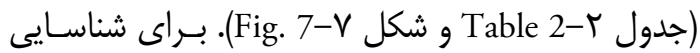

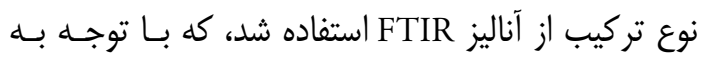
وجود نوارهاى جذبى در ناحيه

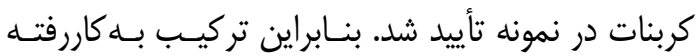

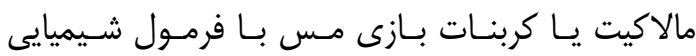
Cu(OH)2 $2 \mathrm{CuCO}_{3}$ F را نشان داد. نوار جذبى كوجى ناحيه

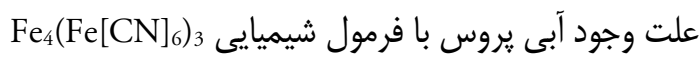

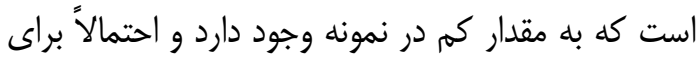
ايجاد يك رنت سبز -آبى استفاده شده است. علاوه بر اين

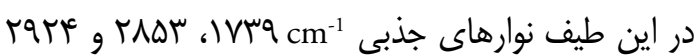
به علت وجود روغن است كه بهعنوان بست رنتَ يا ورنى

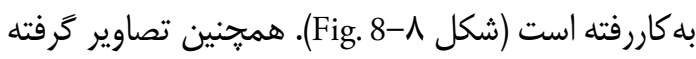
شده با ميكروسكوب پيالريزان در نورهاى مختلف نيز مؤيد

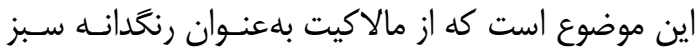
استفاده شده است. مالاكيت دارى رنى سبز كم رنغ تـا

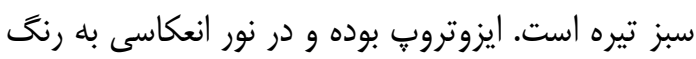

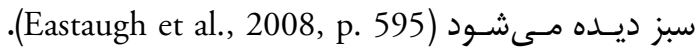

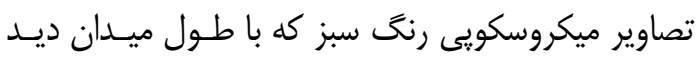
0.375mm مرفته شده است، در شكل 9 آورده شده است.

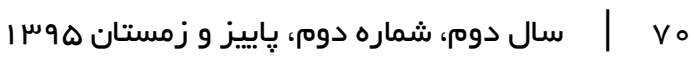




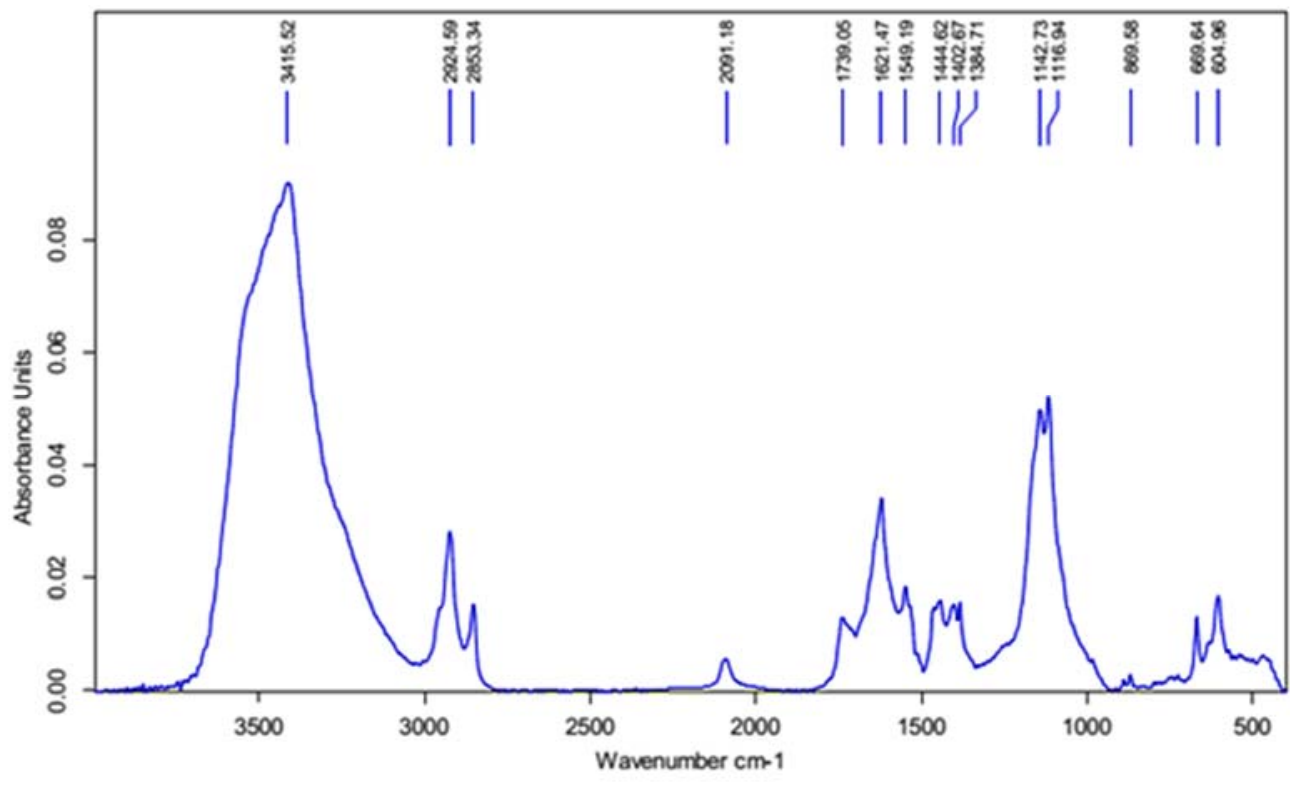

شكل 1 : طيف FTIR رنح سبز كه وجود كربنات، آبى يروس، روغن و گج را نشان مىدهد

Fig. 8: FTIR Spectrum of Green Color, Shows That Carbonate, Prussian blue, Oil and Gypsum

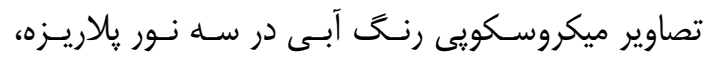
عبورى و انعكاسى آورده شده است. اما نكته جالب توجـهـ دئه

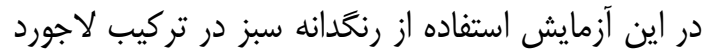

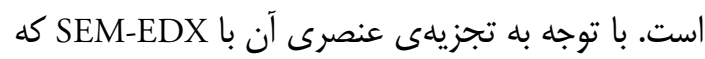
عنصر مس و آهن را نشان مى بهذد، احتمال مىرود همراه

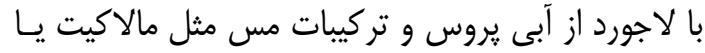

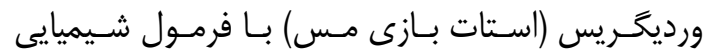
براى تغيير توناليتـه رنــ

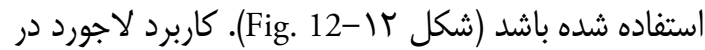

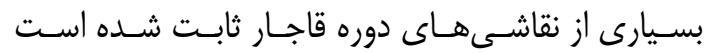
.(Alizadeh, 2012; Bahadori \& Bahrololoomi, 2015)

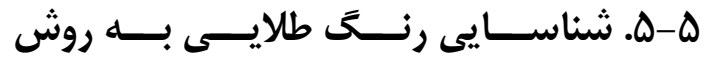
فلورسانس اشعه ايكس ير تابل (micro-XRF) به علت كم بودن مقدار نمونه و عدم امكان نمونهبردارى

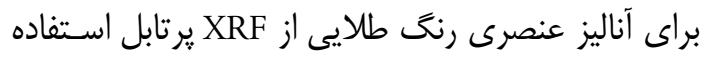

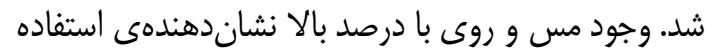

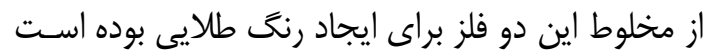

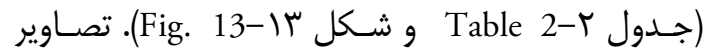

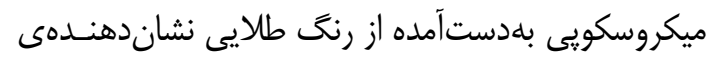
وجود كالكوييريت است كه به دليـل مـات بـودن در نـور

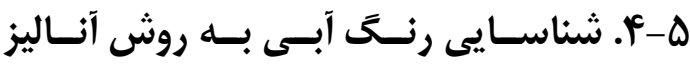
عنصرى EDX

اين رنخ بهراحتى در دماى اتـاق در اسـيد رقيـق ( HCl

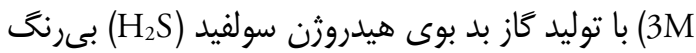

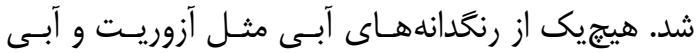

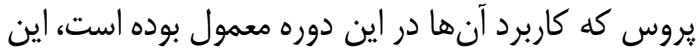

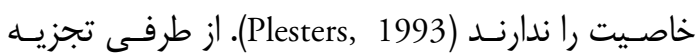

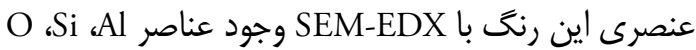

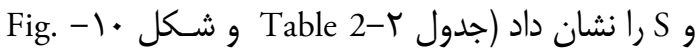

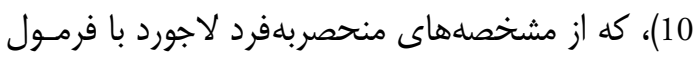

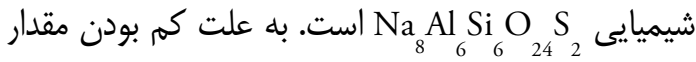
رنخ نسبت به لايهى زير آن، طيـف XRD و FTIR آن

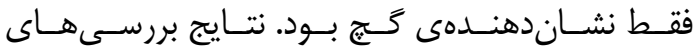

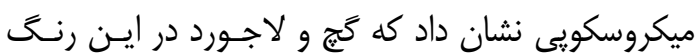

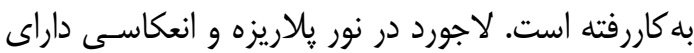

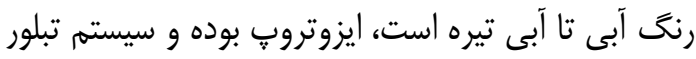

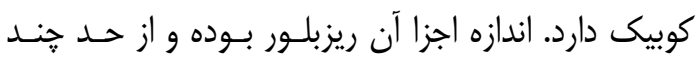
ميكرون فراتر نمىرود و بلهصورت دانههاى گَرد در كنـار

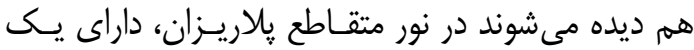
ساختار بلورى مكعبى است، كـه ايزوتـروض (همسـانكَرد)

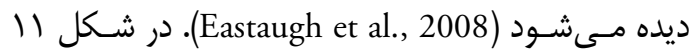



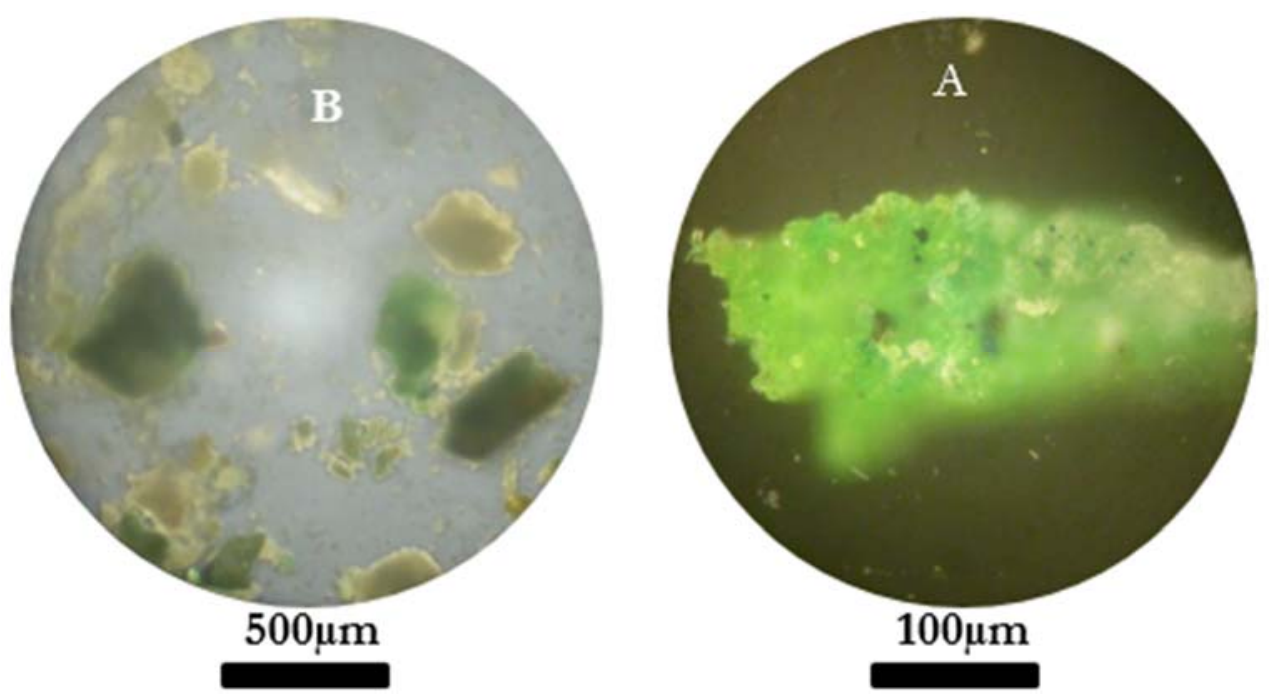

شكل ج: تصاوير ميكروسكويى رنخ سبز در دو نور مختلف A: عبورى، B: B: انعكاسى

Fig. 9: microscopic images green color in two different light A: Transmission, B: Reflection

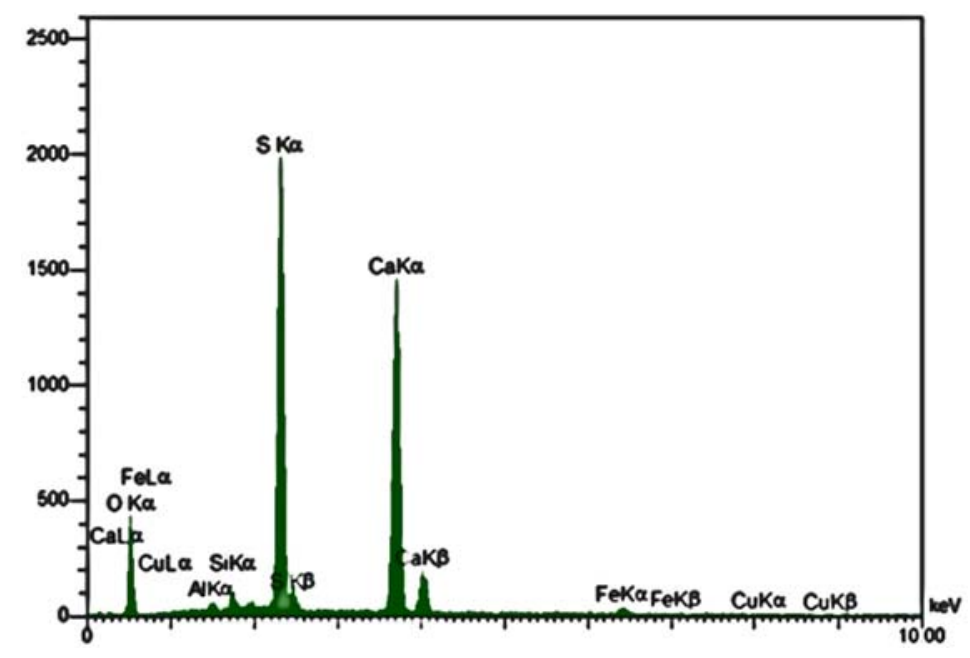

شكل • (: طيف EDX رنغ آبى

Fig. 10: EDX spectrum of blue

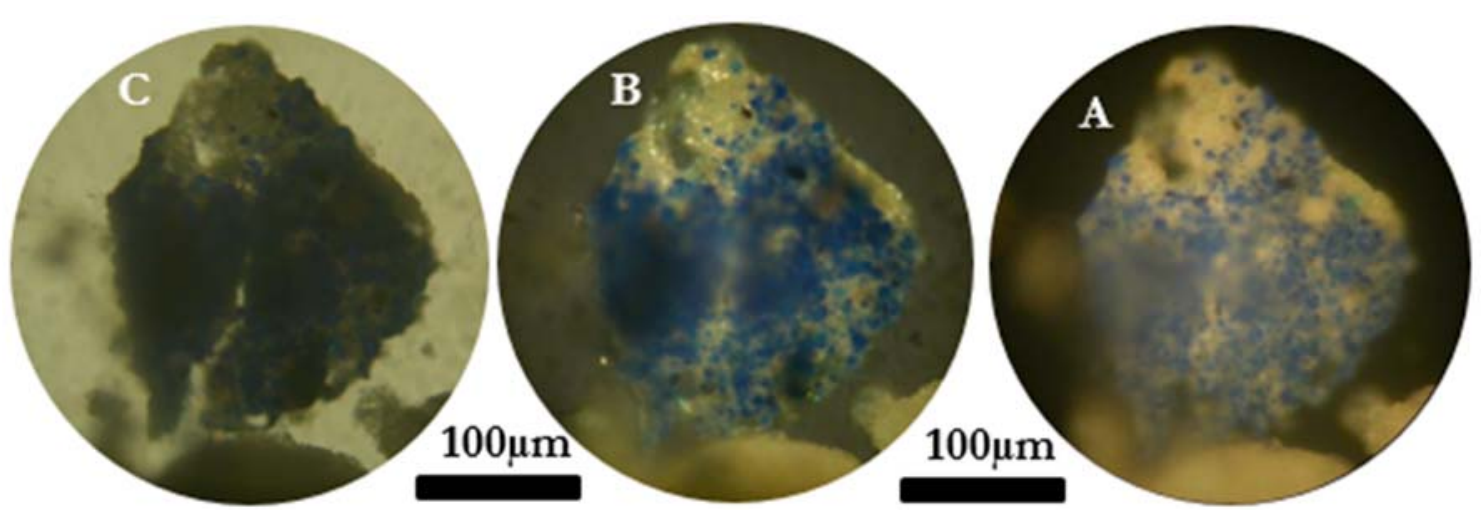

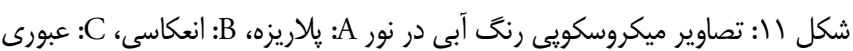

Fig. 11: blue Microscopic Images in the Light: A: Polarizing, B: Reflection C: Transmission 
بنوهن

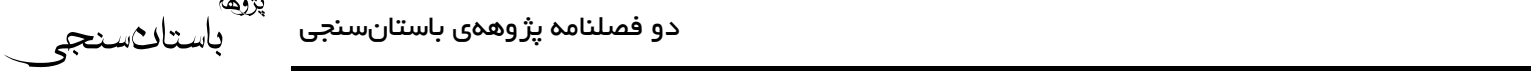

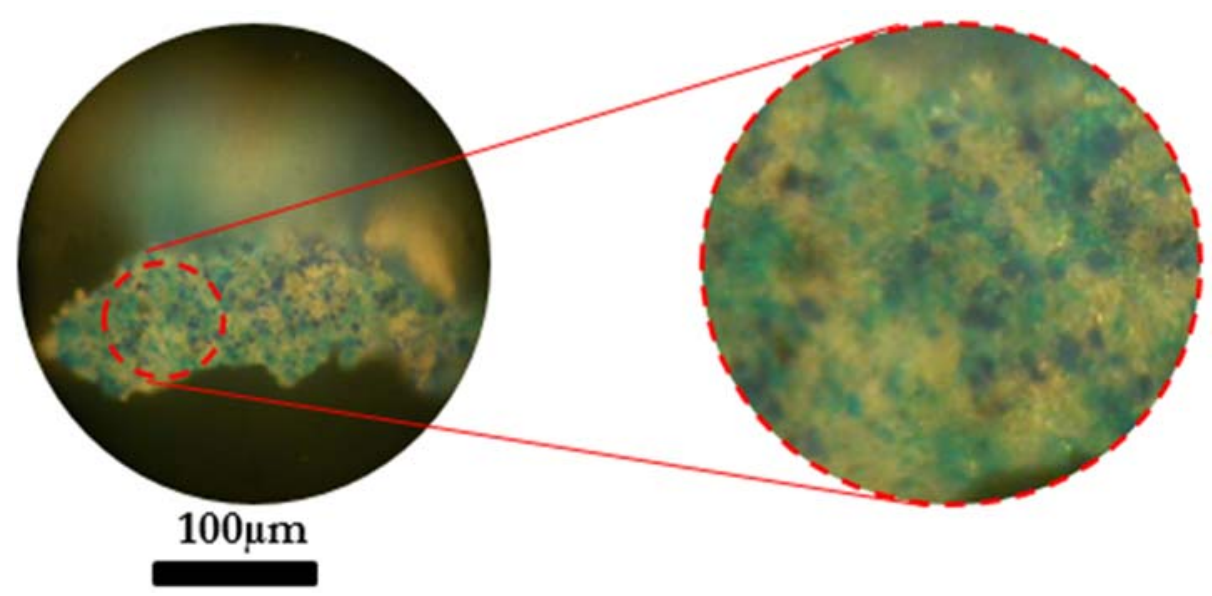

شكل rا: تصاوير ميكروسكوِ نورى كه وجود ذرات سبز را بين ذرات لاجورد نشان مىدهد.

Fig. 12: Polarizing Light microscope images show that green particles between ultramarine particles.

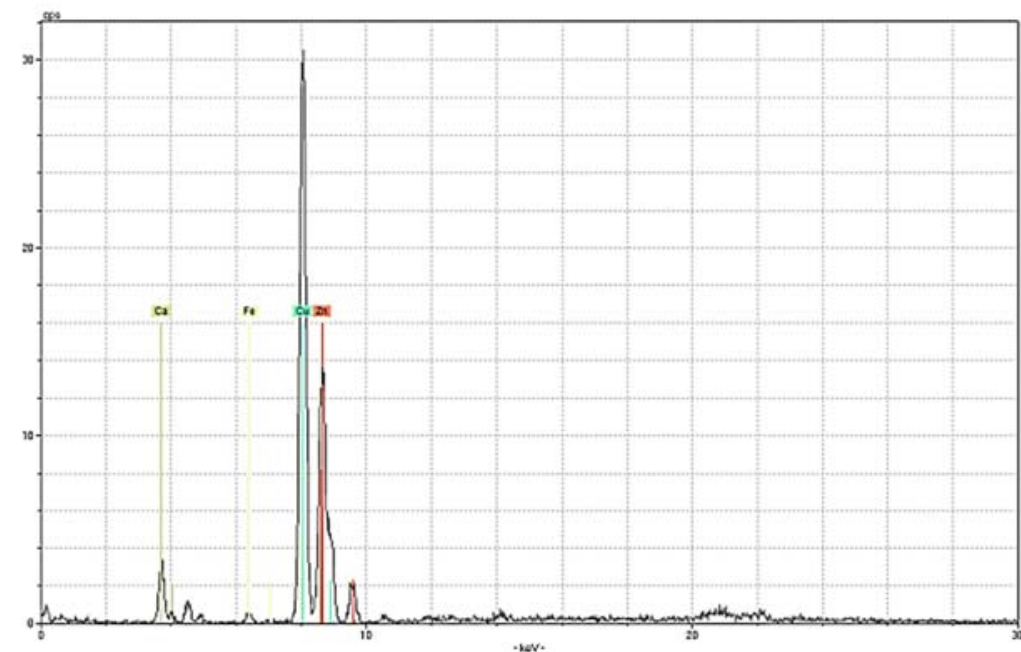

شكل سا: طيف micro- XRF رنح طلايى كه حضور دو عنصر مس و روى را نشان مىدهد.

Fig. 13: micro XRF spectrum of golden color that indicates the presence of both copper and zinc.

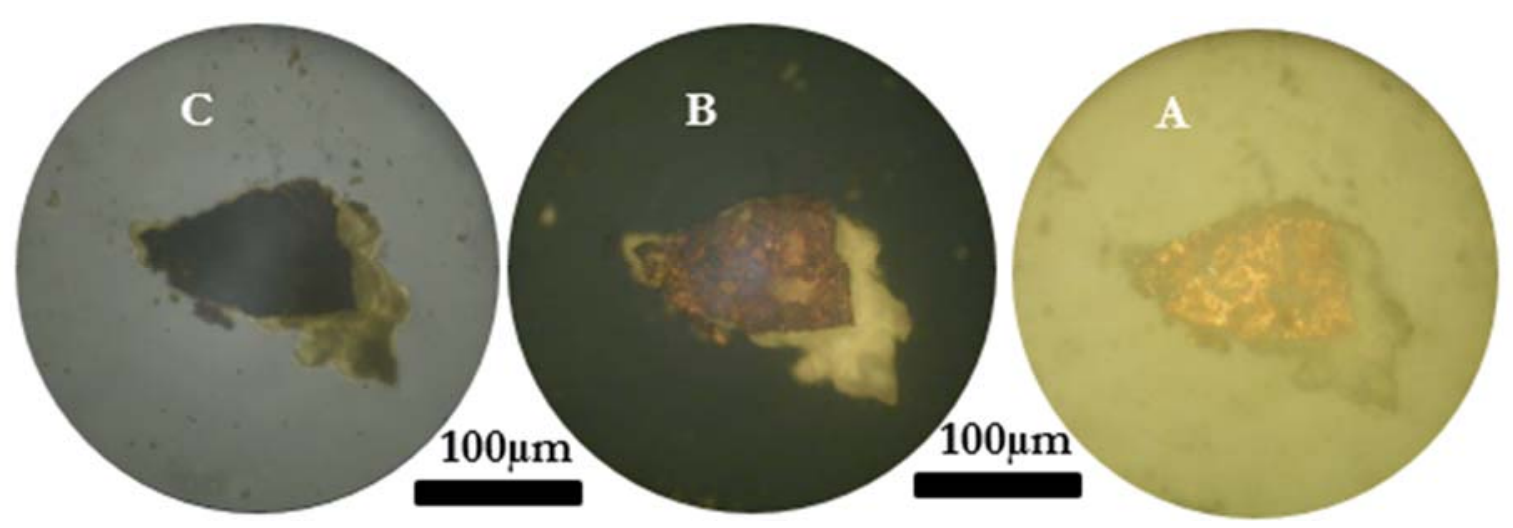

شكل عا: تصاوير ميكروسكويى رنغى طلايى در نور A: لإريزه، B: عبورى، C: انعكاسى، كه وجود كالكوييريت را نشان مىدهد.

Fig. 14: golden Microscopic Images in the Light: A: Polarizing, B: Reflection C: Transmission, showing the presence of chalcopyrite.

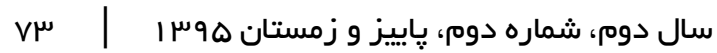


جدول r: نتايج شناسايى رنغَها بر اساس فلورسانس اشعه ايكس يرتابل (micro-XRF) و تفكيك انرزى يرتوايكس (EDX)

Table 2: Results identify colors based portable x-ray fluorescence and Energy-dispersive X-ray (EDX)

\begin{tabular}{|c|c|c|c|c|}
\hline رنغ Color & أبى BLUE & سبز GREEN & Rرمز RED & طلايى GOLDEN \\
\hline $\begin{array}{l}\text { Elements } \\
\text { عناصر }\end{array}$ & $\begin{array}{l}\text { weight percent } \\
\text { Elements W\% }\end{array}$ & $\begin{array}{l}\text { weight percent } \\
\text { Elements W\% }\end{array}$ & $\begin{array}{l}\text { weight percent } \\
\text { Elements W\% }\end{array}$ & $\begin{array}{c}\text { weight percent Elements } \\
\text { W\% }\end{array}$ \\
\hline $\mathrm{O}$ & 14.36 & 25.38 & 28.63 & - \\
\hline $\mathrm{C}$ & - & 12.20 & - & - \\
\hline$S$ & 28.01 & 20.64 & 20.13 & - \\
\hline $\mathrm{Ca}$ & 50.62 & 35.66 & 37.08 & - \\
\hline $\mathrm{Pb}$ & - & - & 10.25 & - \\
\hline $\mathrm{Cl}$ & - & 1.70 & - & - \\
\hline $\mathrm{Cu}$ & 0.24 & 4.42 & - & $*$ \\
\hline $\mathrm{Fe}$ & 5.47 & - & - & - \\
\hline $\mathrm{Al}$ & 0.42 & - & - & - \\
\hline $\mathrm{Si}$ & 0.88 & - & - & - \\
\hline $\mathrm{Zn}$ & - & & & $*$ \\
\hline Type Analysis & EDX & EDX & EDX & micro- XRF \\
\hline Result & ultramarine & $\begin{array}{c}\text { mixture of } \\
\text { malachite and } \\
\text { Prussian blue }\end{array}$ & red lead & $\begin{array}{l}\text { mixture of two metals, } \\
\text { copper and zinc }\end{array}$ \\
\hline
\end{tabular}

لاجورد به همراه تركيبات مس و آهن براى رنــ آبـى و از آلياز مس و روى جهت ساخت رنــ طلايسى استفاده

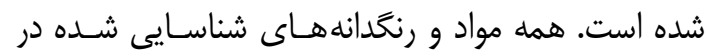
دوره قاجار متداول بوده و بكار مسرفتـه اسـت و تـاريخ

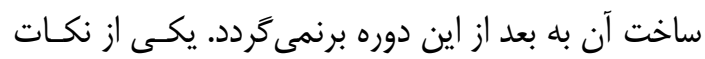

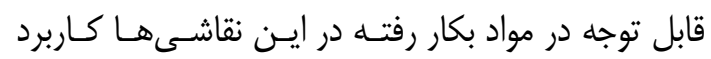

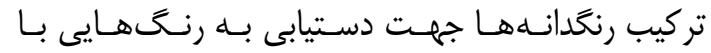

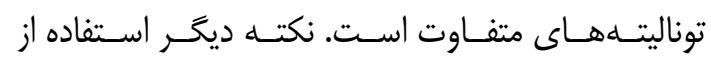

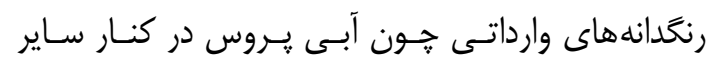
رنحدانهاى سنتى آن دوران است.

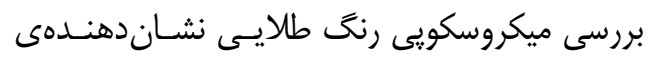

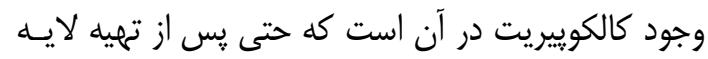

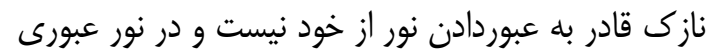

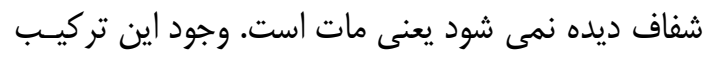

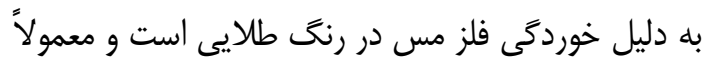

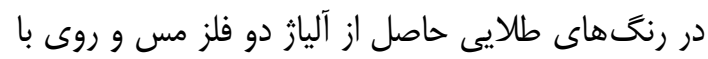
ايجاد رنغ سبز در سطح رنگ طلايى نمايان مى شود.

\section{سياسگزارى}

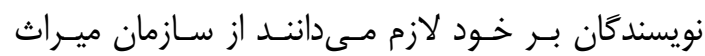

عبورى تيره ديده مىشود. تصـاوير ميكروسـكويى رنــ

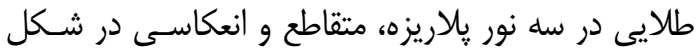

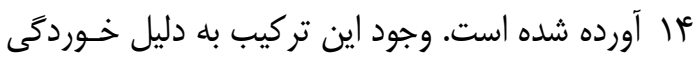

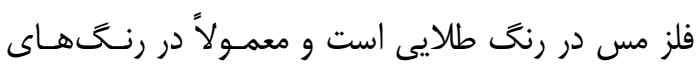

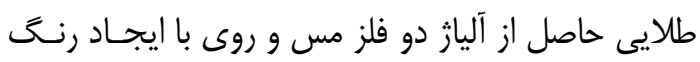

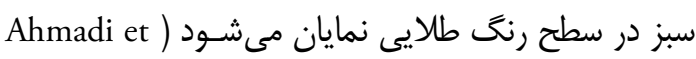

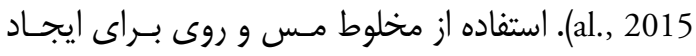

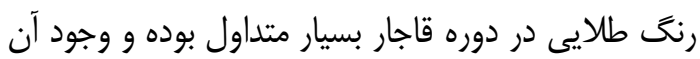

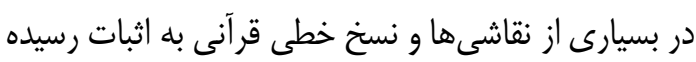

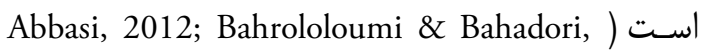
.(2011; Bahadori \& Bahrololoomi, 2013

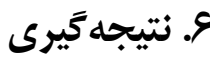

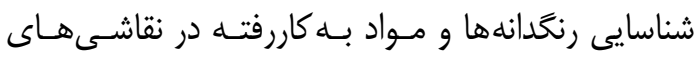

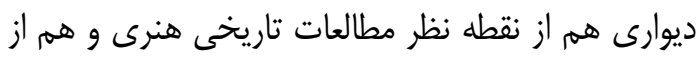
نظر اقدامات حفاظتى اهميت فراوانى دارد. نتايج آناليزهـا

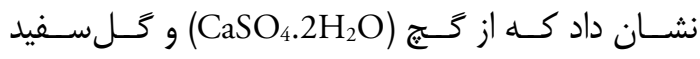
(CaCO 3$)$

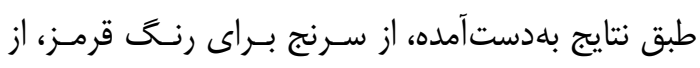

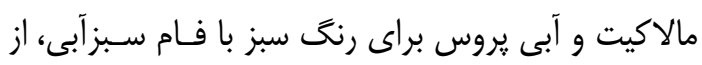

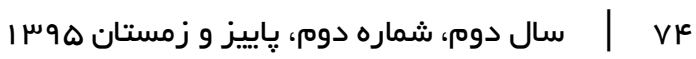




$$
\begin{aligned}
& \text { يثزوهشكده حفاظت و مرمست آثـار تـاريخى -فرهنخَى و }
\end{aligned}
$$

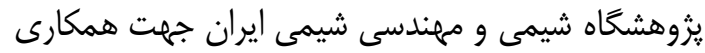

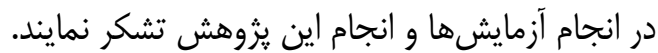

\section{References}

Abbasi, Z. (2012). Technological Study of easel painting of the Qajar period (1794-1925) to provide protection scheme (Unpublished master's thesis). Art University of Tehran. [in Persian]

Ahmadi, H. Abed Esfahani, A., Mortazavi, M., Mousavi, S.M.J. (2015). Recognizing of Golden Counterfeit Beaded on Historical Manuscripts, Study of Process of Destruction the Golden Pigments and Support Sheet, Journal of Maremat \& Memari-e Iran, 4(7), 77-88. [in Persian]

Ahmadi, S., Shokouhi, F., Oliaiy, P., LamehiRachti, M., \& Rahighi, J. (2005). Characterisation of the Wall Painting Pigments of Baghcheh Joogh Castle by PIXE. International Journal of PIXE, 15(03n04), 345-350.

Alizadeh, S. (2012). Investigation and Technological Development in the First Period Qajar Painting Art, Journal of Negare, 7(22), 7384. [in Persian with English abstract]

Aloupi, E., Karydas, A. G., \& Paradellis, T. (2000). Pigment analysis of wall paintings and ceramics from Greece and Cyprus. The optimum use of $\mathrm{X}$-ray spectrometry on specific archaeological issues. X-ray Spectrometry, 29(1), 18-24.

Ayati, A. (2012). Memories of Birjand and Political Events, Tehran: Bahjat Publication, Second Edition. [in Persian]

Ayati, M. H. (1992). Baharestan, Mashhad: Ferdoesi University Press, Second Edition. [in Persian]

Azhand, y. (2006). Qajar era wall painting, Journal of Golestane Honar, 9, 74-81. [in Persian]

Bahadori, R, Ahmadi, S. H. (2012). Scientific Examination of two Iranian Historical Paintings on Wood, Poster presented at the 2nd International Congress Chemistry for Cultural Heritage, Istanbul, Turkey.

Bahadori, R, Bahrololoomi, F. (2013). Archaeometrys investigations of pigments used in paint and mosaic works of the third millennium BC in Iran, Proceedings of the First National Conference on Archaeology of Iran, Birjand, Birjand University of Arts, 1-15. [in Persian]

Bahadori, R, Bahrololoomi, F. (2015). Scientific study of paintings on wood in the house Birjandi. R. Bahadur, \& S. Amin Shirazi (eds.), ninth

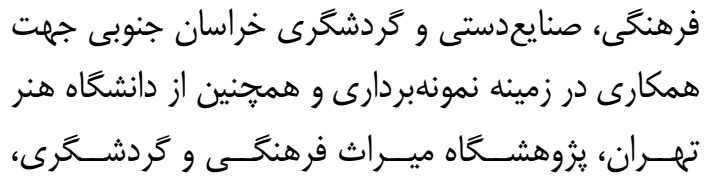

Conference on conservation and restoration of historical monuments and architectural decoration, 1388, Surrey, Tehran: Center for conservation and restoration, 60 -65. [in Persian]

Bahrololoumi, F. Bahadori, R. (2011). Real Gold or Pseudo Gold, Study golden decorations and writings on sheets left by a few manuscripts of the Quran (Safavid to Qajar), Name Baharestan, 12(18-19): 157- 168.

Batter, M. (2010). Structural analysis of pigments wall paintings of Parthian era in the Khajeh Mountain in Sistan, Journal of Crystallography and Mineralogy of Iran, 3, 323-334. [in Persian]

Bicchieri, M., Nardone, M., Russo, P. A., Sodo, A., Corsi, M., Cristoforetti, G., ... \& Tognoni, E. (2001). Characterization of azurite and lazurite based pigments by laser induced breakdown spectroscopy and micro-Raman spectroscopy. Spectrochimica Acta Part B: Atomic Spectroscopy, 56(6), 915-922.

Bruder, R., Detalle, V., \& Coupry, C. (2007). An example of the complementarity of laser-induced breakdown spectroscopy and Raman microscopy for wall painting pigments analysis. Journal of Raman spectroscopy, 38(7), 909-915.

Canby, S. R. (1993). Persian Painting. British Museum Press.

Clark, R. J. (2002). Pigment identification by spectroscopic means: an arts/science interface. Comptes Rendus Chimie, 5(1), 7-20.

Darwish, S. S. (2013). Scientific Investigation of the Materials and Techniques Used In a $19^{\text {th }}$ Century Egyptian Cemetery Wall Painting (Hawsh Al-Basha). International Journal of Conservation Science, 4(2).

Diba, L. S. (1989). Persian Painting in the eighteenth century: tradition and transmission. Muqarnas, 6, 147-160.

Eastaugh, N. (2008). Pigment compendium: a dictionary and optical microscopy of historical pigments. Routledge.

Floor, W. (1999). Art (Naqqashi) and Artists (Naqqashan) in Qajar Persia. Muqarnas, 16, 125154.

Franquelo, M. L., Duran, A., Herrera, L. K., de 
Haro, M. J., \& Perez-Rodriguez, J. L. (2009). Comparison between micro-Raman and microFTIR spectroscopy techniques for the characterization of pigments from Southern Spain Cultural Heritage. Journal of Molecular structure, 924, 404-412.

Ghavami, F. (2013). Technological Colorful Paintings in the East Room Shah Neshin Train Layout

In The House of Hagigi in Esfahan. (Unpublished master's thesis). Restoration of cultural and historical objects. Art University of Tehran. [in Persian]

Gray, B. (1979). The Tradition of Wall Painting in Iran. Highlights of Persian Art, 313-29.

Harandi, D. Taheri, M. H. Sardari, A. Z. (2016). Identification of Pigments of Tal-e Mash Karim Wall Painting at the Chalcolithic Site of Iran, Journal of Color Science and Technology, 9, 187197. [in Persian]

Harley, R. D. (1970). Artists' pigments, c. 16001835; a study in English documentary sources.

Irazola, M., Olivares, M., Castro, K., Maguregui, M., Martínez-Arkarazo, I., \& Madariaga, J. M. (2012). In situ Raman spectroscopy analysis combined with Raman and SEM-EDS imaging to assess the conservation state of 16th century wall paintings. Journal of Raman Spectroscopy, 43(11), 1676-1684.

Ismailian, F. (2013). Technology of monochromatic wall paintings Shah Neshin house bakhradi in Isfahan. (Unpublished master's thesis). Restoration of cultural and historical objects, Art University of Tehran.

Josa, V. G., Bertolino, S. R., Laguens, A., Riveros, J. A., \& Castellano, G. (2010). X-ray and scanning electron microscopy archaeometric studies of pigments from the Aguada culture, Argentina. Microchemical Journal, 96(2), 259-268.

Mazzocchin, G. A., Agnoli, F., Mazzocchin, S., \& Colpo, I. (2003). Analysis of pigments from Roman wall paintings found in Vicenza. Talanta,
61(4), 565-572.

Mcbride, C. (2002). Pigment Particle \& Fiber Atlas for Paper Conservators. Getty Trust Postgraduate Fello.

Mojtahed-Zadeh, P. (2004). The Small Players of the Great Game: The Settlement of Iran's Eastern Borderlands and the Creation of Afghanistan. Routledge.

Mozaffari, A., Bahadory, R., Bahreman, A. R. (2010). Restoration and laboratory investigations Vitrai paintings Rashvand Qazvin house, Journal of Assar, 51, 74-82.

Porter, E. (2014). Traditions and techniques of painting and illustration. (Z. Rajabi, Trans.). Tehran: publication of the Academy of Arts. [in Persian]

Riederer, J., Schweppe, H., Winter, J., Feller, R. L., Johnston-Feller, R. M., Berrie, B. H., ... \& Laver, M. (1997). Artists' pigments: a handbook of their history and characteristics, v. 3.

Vandenabeele, P., Bodé, S., Alonso, A., \& Moens, L. (2005). Raman spectroscopic analysis of the Maya wall paintings in Ek'Balam, Mexico. Spectrochimica Acta Part A: Molecular and Biomolecular Spectroscopy, 61(10), 2349-2356.

Vatandoost, R., Bahadory, R. (1998). Identification of Compounds Used in a Wall Painting by Using Fourier-Transform Infrared Spectroscopy, Proceedings of the Conservation of HistoricalCultural Center. Tehran, 98-101.

Vatandoost, R., Beheshti, S.M., Nayeri, P. (2013). A Review on the Foundations of Traditional Wall Paintings Restored in Iran, Journal of Bag nazar, 10(27), 71-82.

Yate, C. E. (1900). Khurasan and Sistan. W. Blackwood.

Zeng, Q. G., Zhang, G. X., Leung, C. W., \& Zuo, J. (2010). Studies of wall painting fragments from Kaiping Diaolou by SEM/EDX, micro Raman and FT-IR spectroscopy. Microchemical Journal, 96(2), 330-336. 